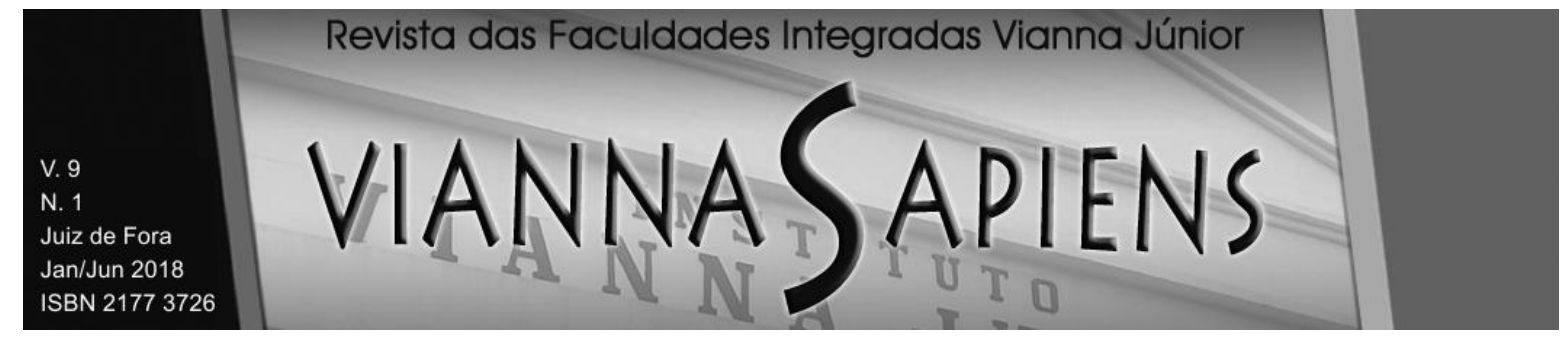

\title{
ANÁLISE DAS PROPAGANDAS E REPORTAGENS RELACIONADAS À SEGURANÇA AUTOMOTIVA PUBLICADAS NA REVISTA QUATRO RODAS \\ DOI: 10.31994/rvs.v9i1.264
}

\author{
Diego Faria Martins ${ }^{1}$ \\ Tharcisio Alexandrino Caldeira ${ }^{2}$ \\ Andréia Aparecida Albino ${ }^{3}$
}

\section{RESUMO}

A sensação de insegurança no trânsito pode ser identificada pela constante divulgação de reportagens que a desencadeiam, bem como pela expressiva presença de propagandas de produtos de segurança automotiva em diversas mídias. Este trabalho buscou analisar a evolução de propagandas e reportagens sobre segurança automotiva nas edições da revista Quatro Rodas, investigando todas as 647 edições disponíveis online. A pesquisa recorreu à ANOVA, à Análise de Séries Temporais e à Análise de Conteúdo (AC) para analisar os dados. Os resultados mostraram um significativo aumento do percentual de propagandas sobre segurança desde 1990. As reportagens sobre segurança não expressaram comportamento semelhante. Identificou-se uma relação significativa entre o percentual de propagandas sobre segurança e seus próprios valores, defasados em três edições, evidenciando a influência das campanhas publicitárias durante este

\footnotetext{
${ }^{1}$ Especialista em Administração e Gestão Pública, Fiscal Sanitário da Prefeitura Municipal de Rio Pomba. E-mail: diego.faria.martins@hotmail.com. ORCID: https://orcid.org/0000-0002-3370-2303.

${ }^{2}$ Doutor em Administração pela PUC-Rio, Professor do Departamento Acadêmico de Ciências Gerenciais do IF Sudeste MG - Campus Rio Pomba. E-mail: tharcisio.caldeira@ifsudestemg.edu.br. ORCID: https://orcid.org/0000-0001-5760-3302.

${ }^{3}$ Doutora em Administração pela PUC-Rio, Professora do Departamento Acadêmico de Ciências Gerenciais do IF Sudeste MG - Campus Rio Pomba. E-mail: andreia.albino@ifsudestemg.edu.br. ORCID: https://orcid.org/0000-0002-1947-6928.
} 


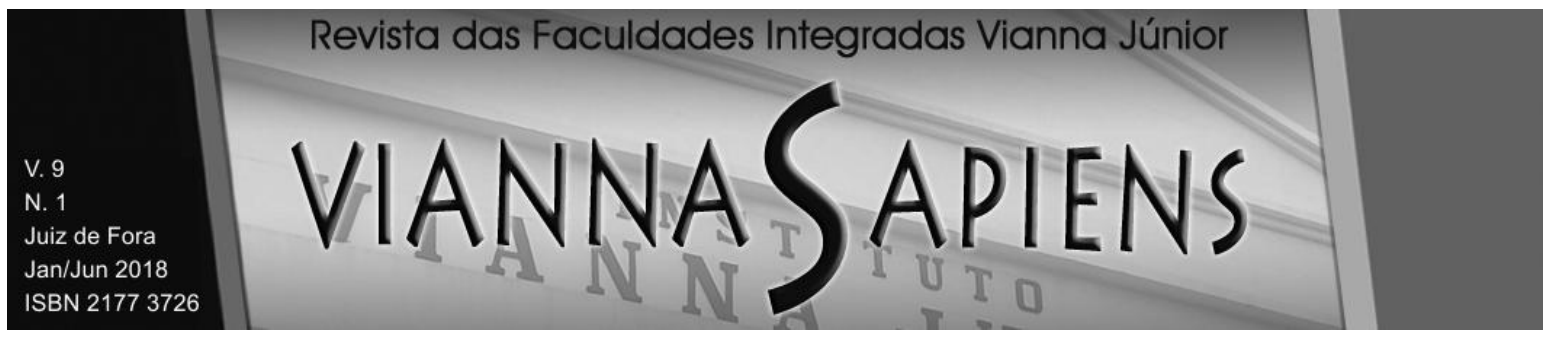

período. A AC constatou que anúncios relacionados às sensações de tranquilidade e alerta são os mais frequentes em todas as décadas.

\section{PALAVRAS-CHAVE: SEGURANÇA AUTOMOTIVA. COMPORTAMENTO DO CONSUMIDOR. ANÁLISE DE CONTEÚDO. PROPAGANDAS. REPORTAGENS.}

\section{INTRODUÇÃO}

Impulsionado pelo desejo de consumo e também pela predominância da malha rodoviária no país, o automóvel é considerado um dos principais objetos de desejo do brasileiro (MENEGUIN, 2016). Aparece como principal facilitador no transporte de pessoas e cargas, além de proporcionar aos usuários sensações de liberdade, virilidade, comodidade e independência.

Pessôa (2013), em seu estudo sobre as relações entre consumo e segurança (ou insegurança), afirma que grande parte dos consumidores, conduzidos pela necessidade de se sentirem seguros, fomentam gradativamente a produção de sistemas que tenham função de eliminar ou diminuir sua sensação de insegurança, satisfazendo seus desejos de consumo como alternativa para adiar frustrações e sentimentos como medo e terror.

Dentre os ambientes capazes de transmitir a sensação de insegurança à sociedade, pode-se destacar o trânsito brasileiro, impulsionado principalmente pela mídia, responsável por publicar diariamente reportagens sobre segurança automotiva, expondo, em sua grande maioria, casos de acidentes de trânsito principalmente causados por descuidos e falhas humanas (DAMATTA, 2010; STEVENS, 2013).

De acordo com Dearo (2014), o Brasil ocupa a $42^{\text {a }}$ posição no ranking mundial de acidentes de trânsito, se feita a proporção do número de acidentes pela população do país, sendo o $4^{\circ}$ em número absoluto de acidentes, atrás apenas de 


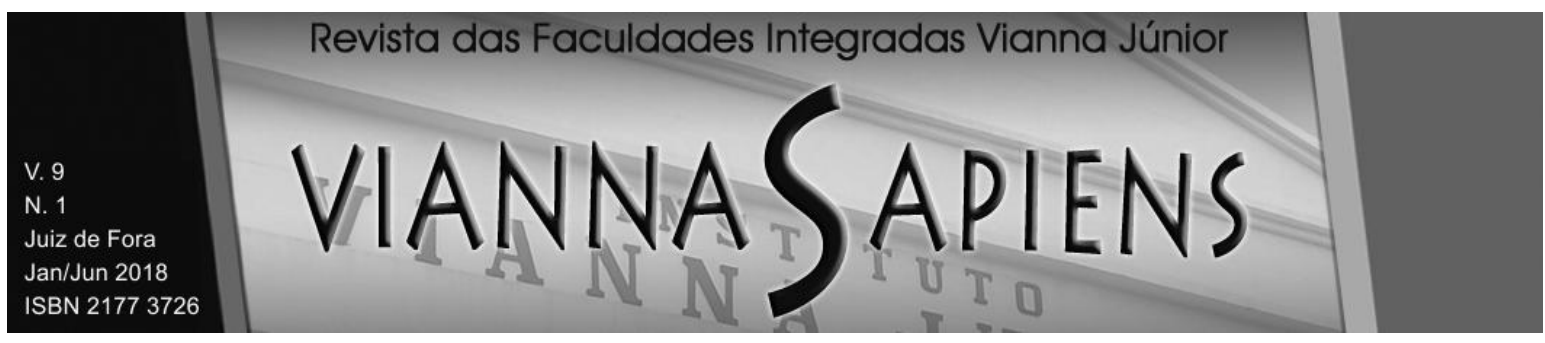

China, Índia e Nigéria. Segundo a Organização das Nações Unidas no Brasil ONUBR (2015), o Brasil é o país que detém o maior índice de acidentes de trânsito por habitante da América do Sul.

A importância da segurança automotiva para o governo brasileiro, ainda que tardia, é evidenciada pela atualização da legislação, mais especificamente pela entrada em vigor no ano de 2014 das leis federais no 11.910 e 12.006 , que tratam da obrigatoriedade de todos os carros produzidos no país e importados conterem airbag (BRASIL, 2009a) e freios ABS - antilock braking system (sistema antitravamento de frenagem) (BRASIL, 2009b).

Ao se analisar a pirâmide da hierarquia das necessidades humanas, desenvolvida por Maslow (1970) e ilustrada por diversos autores, tais como Kotler e Armstrong (2007), também é possível perceber a importância dada às necessidades de segurança, posto que estas aparecem no segundo nível da hierarquia, acima somente das necessidades fisiológicas e abaixo de necessidades como sociais e de autoestima.

Okigbo, Martin e Amienyi (2005) constataram a relação direta entre o modo como os meios de comunicação em massa trabalham e o comportamento da sociedade. Para os mesmos, a cultura e os valores de uma sociedade podem estar inseridas em seus anúncios.

Dentro do contexto de comunicação, pode se destacar a importância da Revista Quatro Rodas. Esta possui periodicidade de publicação mensal (publicando duas edições no mês de dezembro, desde 2004) e é uma das mais influentes entre as revistas de circulação no país voltadas para o ramo automotivo. De acordo com informações divulgadas pela ANER - Agência Nacional de Editores de Revistas (2014), a revista Quatro Rodas foi a revista automotiva de maior tiragem no ano de 2014 (mais de 250 mil exemplares de janeiro a setembro), seguida da revista Auto Esporte (pouco mais de 105 mil exemplares, durante o mesmo período).

Por ter disponível em seu site o acervo digital, é possível que o internauta acesse gratuitamente desde a primeira edição (publicada em agosto de 1960) até 


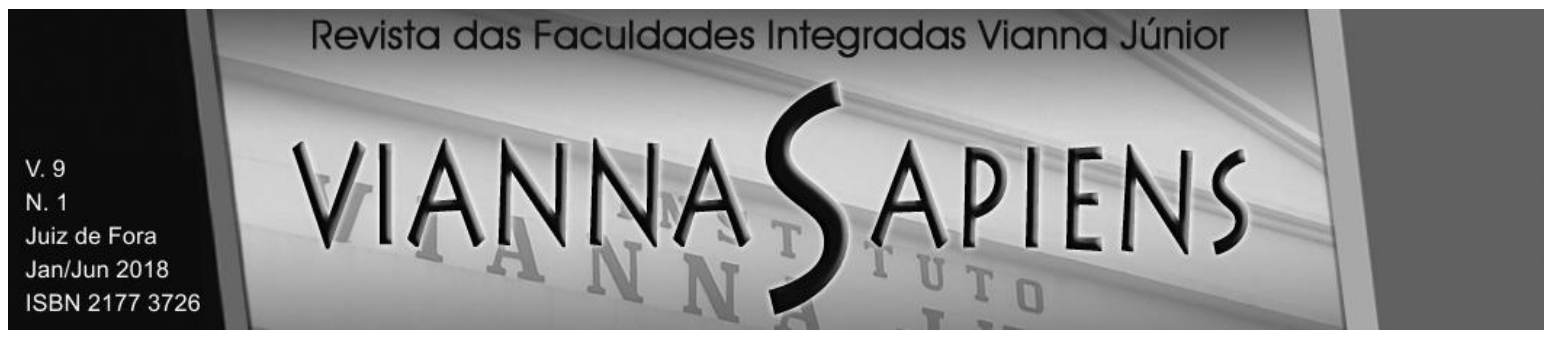

edição 647 (de outubro de 2013), podendo, inclusive, efetuar o download das páginas. Ao todo são 53 anos disponíveis para acesso.

Diante do exposto, esta pesquisa procurou investigar como a segurança automotiva foi abordada em reportagens e propagandas presentes nas 647 edições da revista Quatro Rodas disponibilizadas no acervo digital. Além disso, esta pesquisa também procurou analisar, de maneira mais profunda, como o conteúdo das propagandas sobre segurança automotiva da referida revista evoluiu ao longo do período entre agosto de 1960 e outubro de 2013.

\section{REFERENCIAL TEÓRICO}

\subsection{A mídia e a propaganda}

A fim de atrair públicos-alvo específicos, os anunciantes utilizam diversos canais de comunicação para veicular suas mensagens. Cada tipo de mídia possui características singulares e usuários distintos. Para Crocco et al. (2010), mídia seria qualquer meio de comunicação por meio do qual a mensagem transmitida pelo anunciante atinge $o$ cliente.

Kotler e Armstrong (2007), Rocha e Christensen (2008) e Las Casas (2010) ilustram os perfis dos principais tipos de mídia (internet, televisão, rádio, jornais, mala direta, outdoor e revistas), bem como evidenciam suas vantagens e limitações. Destacam-se as características das revistas, tidas como um dos principais meios de comunicação impresso.

A propaganda é uma ferramenta do composto promocional amplamente eficaz, utilizada para viabilizar o processo de comunicação entre organizações e clientes, sendo definida por Crocco et al. (2010, p. 190) como "qualquer forma paga e não pessoal de divulgação de um produto, feita por um patrocinador identificado, por intermédio de uma mídia". 


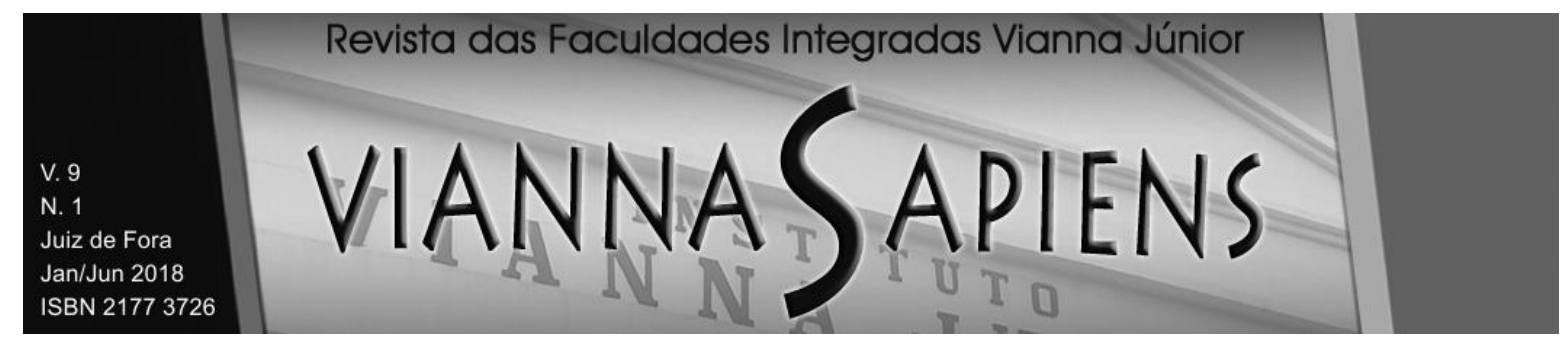

O objetivo principal das propagandas é atrair a atenção de consumidores atuais e potenciais, para que estes reajam aos estímulos recebidos (KOTLER; ARMSTRONG, 2007). As propagandas buscam propagar ideias com intuito de convencer, alertar, motivar, informar, persuadir e conscientizar determinadas pessoas visando principalmente influenciar mudanças de comportamento, além de transmitir lembranças e informações a fim de induzir indivíduos a utilizarem certos produtos/serviços (ROCHA; CHRISTENSEN, 2008; STEVENS, 2013).

De acordo com Pessôa (2013), a propaganda possuiu relação direta com o consumo, visto que age como intermediária nas relações entre os consumidores e produtos/marcas. Okigbo, Martin e Amienyi (2005) evidenciam que a cultura e os valores de uma sociedade podem ser espelhados pelo conteúdo de suas propagandas e, como os mesmos constataram, os gêneros das propagandas norte americanas contemporâneas dispostas nos mais variados meios de comunicação refletem os valores culturais presentes em sua sociedade (destacando, principalmente, o individualismo e visão positiva do futuro).

Nos últimos anos, tem-se identificado diversas publicações de trabalhos que utilizaram a técnica de Análise de Conteúdo, que é uma das técnicas empregadas para atingir os objetivos da presente pesquisa, para analisar as mensagens dispostas em propagandas de diferentes produtos/marcas ou serviços e seus propósitos. Mastroianni et al. (2008) analisaram anúncios de medicamentos psicoativos, Acevedo et al. (2010) se propuseram a identificar o papel feminino contido em comerciais entre 1973 e 2008, Faria et al. (2014) analisaram papéis representados por afrodescendentes em propagandas de jornais paulistas e Bazanini, Rossi e Plantulo (2005), Vieira (2006) e Vieira e Petroll (2007) realizaram Análise de Conteúdo em propagandas de empresas prestadoras de serviços.

As revistas compõem parte da mídia impressa, tema abordado a seguir. 


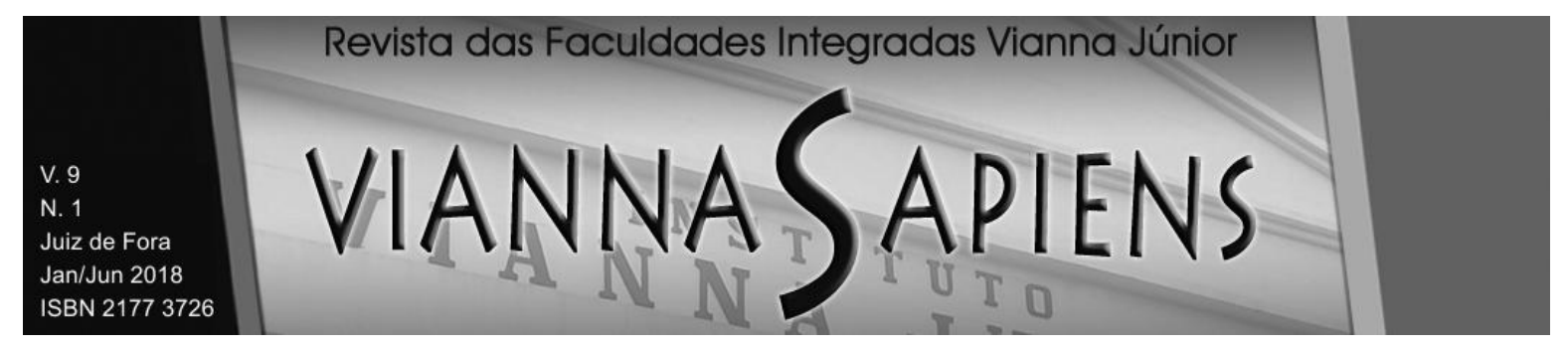

\subsubsection{As revistas como representantes da mídia impressa}

De acordo com Cobra (2009), as revistas demonstram superioridade aos jornais, sendo a principal mídia impressa. No que diz respeito às formas de comunicação em geral, vale ressaltar a crescente utilização da tecnologia, principalmente o uso da internet e suas facilidades (CHERIAN, 2015). Revistas brasileiras como Veja, Exame, Administradores, Todateen, PeGn e a própria Quatro Rodas se adaptaram a essa evolução, ofertando a opção de compra e visualização de exemplares online em smartphones, tablets e computadores, solução alternativa à revista de papel.

Jain et al. (2017), ao pesquisar o comportamento dos leitores de revistas nas mídias sociais, identificaram que grande parte dos leitores, ao indicarem motivos para acessar as mídias sociais de suas revistas preferidas, buscam oportunidades de recomendações de produtos relevantes, bem como obter mensagens direcionadas. O Quadro 01 resume as principais vantagens e desvantagens das revistas.

Quadro 01 - Vantagens e Desvantagens das Revistas.

\begin{tabular}{|c|c|}
\hline Vantagens & Desvantagens \\
\hline Seletividade do público-alvo & Limitada cobertura e frequência \\
\hline Ausência de concorrência no & Atualidade limitada devido à periodicidade \\
\hline Personalização & Custo alto de inserção de anúncios \\
\hline Receptividade facilitada & $\begin{array}{l}\text { Não há garantia da posição do grau de } \\
\text { receptividade do anúncio }\end{array}$ \\
\hline $\begin{array}{l}\text { Maior aceitação dos anúncios devido à } \\
\text { fidelidade à revista }\end{array}$ & $\begin{array}{l}\text { Longo tempo entre a recepção do anúncio por } \\
\text { parte do cliente e a efetivação da compra }\end{array}$ \\
\hline $\begin{array}{l}\text { A vida longa do periódico permite que seja } \\
\text { visualizado mais de uma vez }\end{array}$ & $\begin{array}{l}\text { Impossibilidade de veiculação de anúncios "de } \\
\text { última hora" devido ao tempo necessário para } \\
\text { preparar o periódico }\end{array}$ \\
\hline
\end{tabular}

Fonte: Elaborado pelos autores com base em Kotler e Armstrong (2007), Cobra (2009) e Las Casas (2010).

O público leitor de revistas é, segundo Celinski e Skura (2018), mais segmentado que o de jornais, dada a existência de revistas para atenderem a gostos bastante específicos. As revistas, quando dirigidas a um público altamente específico, tendem a atingir adequadamente os objetivos delineados pelas agências 


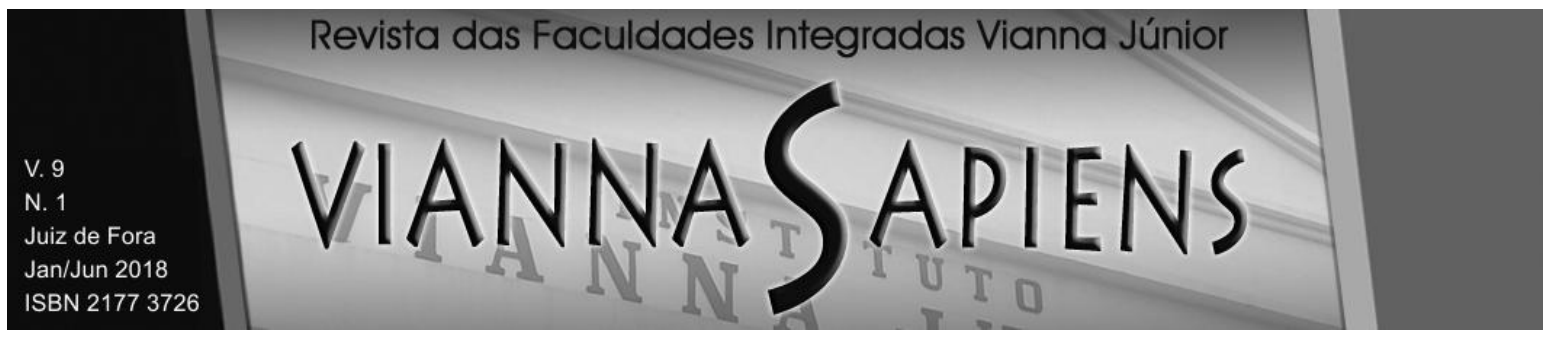

publicitárias ao criarem seus anúncios (ROCHA; CHRISTENSEN, 2008; COBRA, 2009).

\subsection{Segurança automotiva}

O conceito de segurança trazido pelo dicionário Michaelis (2016) se aproxima de um estado livre de risco, garantia, proteção, certeza, infalibilidade, confiança, firmeza.

O automóvel aparece como um dos principais símbolos do século $X X$, tendo primeiro registro em território brasileiro no ano de 1891, dirigido por Alberto Santos Dumont (MELO, 2008). Marín e Queiroz (2000) corroboram mencionando o automóvel como um artigo de consumo, símbolo de status social, incentivado principalmente pelas propagandas das economias capitalistas que enaltecem qualidades como a capacidade de mobilidade individual e prosperidade material proporcionada pelo mesmo. Para Stevens (2013), o automóvel atende aos desejos individuais de poder, velocidade, status, liberdade, independência e prestígio. Para Meneguin (2016), no Brasil, este não só se posiciona como objeto de desejo dos indivíduos, mas até mesmo do Estado, que costuma ver no automóvel uma fonte de progresso.

As cidades, muito devido a seu crescimento acelerado e aumento do poder aquisitivo da população de um modo geral, possuem elevados volumes de veículos em circulação (SASAKI; FANTIN, 2012). De acordo com Marín e Queiroz (2000), o aumento na produção e consumo de automóveis resulta em transformações sociais, além de estar ligado diretamente no aumento dos acidentes de trânsito, os quais, por sua vez, resultam em altos custos sociais e econômicos. Isto costuma justificar a necessidade de intervenção do Estado a fim de elaborar e executar políticas públicas específicas visando reduzir acidentes.

Os acidentes de trânsito são considerados a principal causa de morte entre os jovens em idade produtiva a nível mundial, tratados inclusive como problema de 


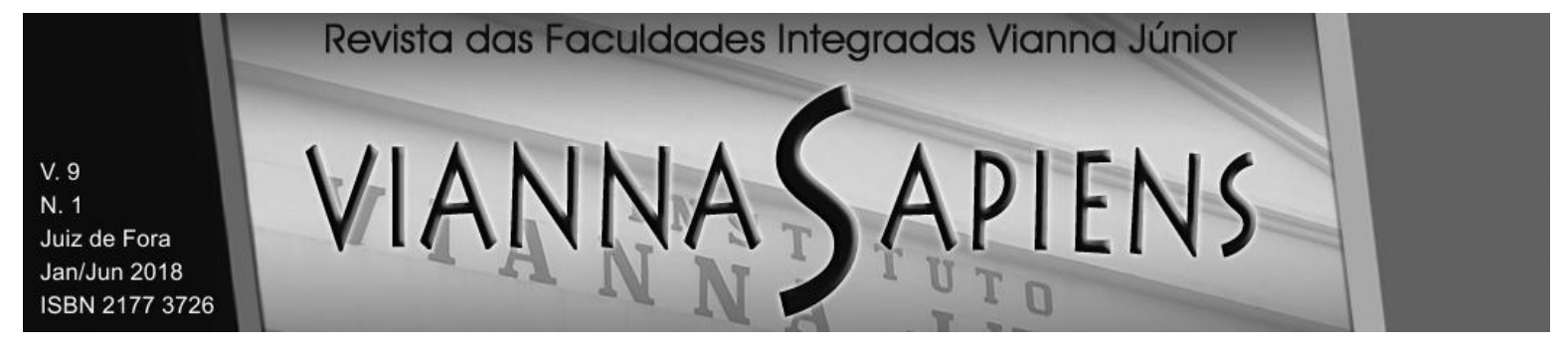

saúde pública, o que ressalta a importância da criação de medidas que visem principalmente a prevenção, com objetivo de reduzir a ocorrência de acidentes de trânsito e, consequentemente, a taxa de mortalidade, além de danos pessoais, sociais e econômicos (ARAUJO; MALLOY-DINIZ; ROCHA, 2009; SASAKI; FANTIN, 2012; MESQUITA FILHO, 2012; GONZÁLEZ-LÓPEZ; RODRÍGUEZ-GÁZQUEZ; LOMAS-CAMPOS, 2014). Gold (1998) e Araújo, Malloy-Diniz e Rocha (2009) discorrem sobre os principais fatores causadores de acidentes de trânsito, ilustrados no Quadro 02.

Quadro 02 - Fatores causadores de acidentes de trânsito.

\begin{tabular}{|l|l|}
\hline Fatores humanos & $\begin{array}{l}\text { Comportamento inadequado dos envolvidos (tensão nervosa, uso } \\
\text { de álcool e outras drogas, desconhecimento do trajeto percorrido, } \\
\text { distrações, tráfego em baixas ou altas velocidades, idade - } \\
\text { juventude ou idade avançada). }\end{array}$ \\
\hline $\begin{array}{l}\text { Fatores relativos aos } \\
\text { veículos }\end{array}$ & $\begin{array}{l}\text { Precário estado operacional, faróis desajustados, freios, limpadores } \\
\text { de para-brisa, pneus gastos, problemas na direção, amortecedores } \\
\text { em estado precário, problemas mecânicos. }\end{array}$ \\
\hline $\begin{array}{l}\text { Fatores relativos à via, meio } \\
\text { ambiente ou ambiente } \\
\text { construído }\end{array}$ & $\begin{array}{l}\text { Precária sinalização (ausente ou ineficiente), curvas acentuadas, } \\
\text { pavimentação lisa, precária luminosidade (ausente ou ineficiente). }\end{array}$ \\
\hline $\begin{array}{l}\text { Fatores institucionais ou } \\
\text { sociais }\end{array}$ & $\begin{array}{l}\text { Legislação mal regulamentada, fiscalização ineficiente, precária } \\
\text { educação para o trânsito. }\end{array}$ \\
\hline
\end{tabular}

Fonte: Elaborado pelos autores com base em Gold (1998) e Araújo, Malloy-Diniz e Rocha (2009).

É evidente que a segurança automotiva tem vital importância, porém, em muitos casos, os consumidores tendem a ignorar sua necessidade. Ressalta-se também o significativo papel da mídia (publicidade e propaganda) nas decisões dos consumidores e na formação de opinião da sociedade, fato que justifica o interesse desta pesquisa em explorar o universo das propagandas e reportagens sobre segurança expostas na revista Quatro Rodas. 


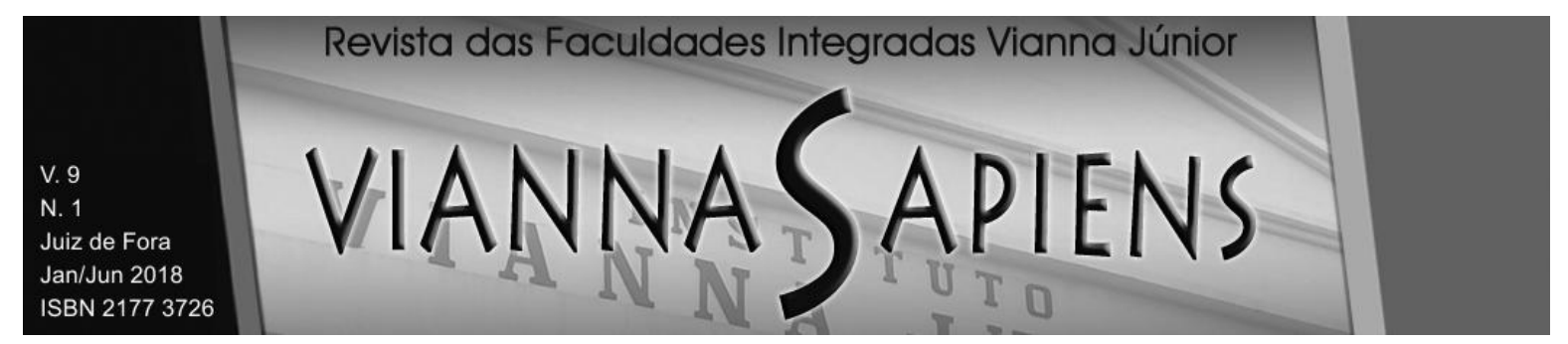

\section{METODOLOGIA}

Por ter observado o comportamento dos anúncios e das reportagens disponíveis nas edições da revista Quatro Rodas e efetuado comparações ao longo do tempo, o presente trabalho pode ser considerado como uma pesquisa descritiva, observando o que preconiza Gil (2009). Esta pesquisa também pode ser classificada como exploratória de acordo com os critérios propostos por Vergara (2010), uma vez que a segurança automotiva é uma área na qual existe pouco conhecimento acumulado e sistematizado no Brasil. Quanto aos meios de investigação, Vergara (2010) indica que esta pesquisa também pode ser considerada bibliográfica, posto que o levantamento dos dados das duas pesquisas se deu em material já elaborado (propagandas e reportagens).

\subsection{Coleta e preparação dos dados}

As reportagens (relacionadas ao tema segurança automotiva) e propagandas (todas, independente do assunto) presentes nas edições da revista Quatro Rodas foram gravadas em arquivos ".pdf", catalogados de acordo com edição, ano e década da revista. Ao todo foram contabilizadas 42.709 propagandas (que, após categorização de acordo com os critérios expostos no Quadro 03, foram identificadas 5.361 propagandas correlatas ao tema segurança automotiva) e 909 reportagens.

Quadro 03 - Critérios de categorização das propagandas da Revista Quatro Rodas

\begin{tabular}{|l|l|}
\hline Veículos - Segurança & $\begin{array}{l}\text { Anúncios relacionados a veículos que fazem algum tipo de } \\
\text { menção ou apelo à segurança. }\end{array}$ \\
\hline Veículos - Outros Assuntos & $\begin{array}{l}\text { Anúncios relacionados a veículos, peças, acessórios, serviços, } \\
\text { etc., que não mencionem segurança. }\end{array}$ \\
\hline Não - Veículos & $\begin{array}{l}\text { Anúncios diversos, que não possuem relação alguma com } \\
\text { automóveis. }\end{array}$ \\
\hline
\end{tabular}

Fonte: Elaborado pelos autores. 


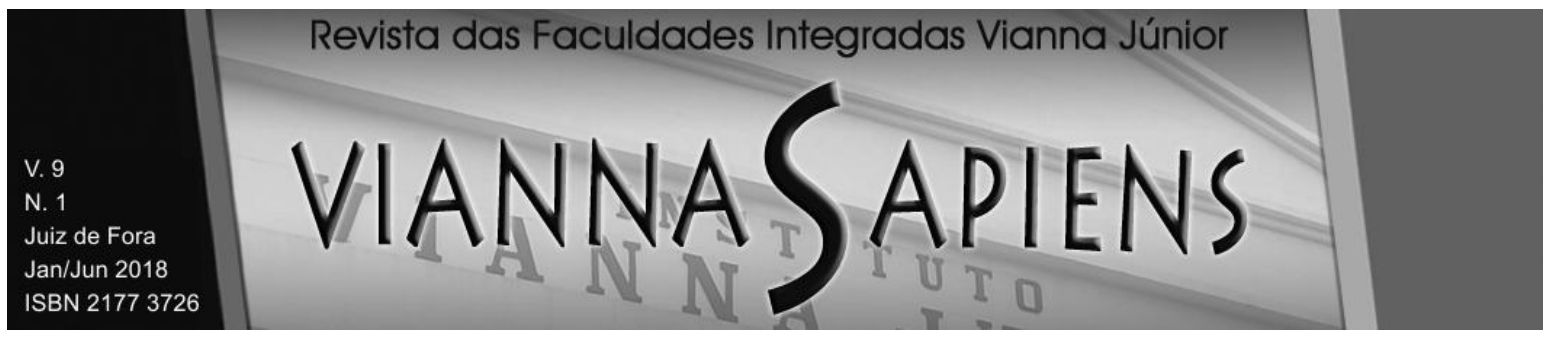

\subsection{Tratamento dos dados}

Os dados coletados foram tratados por métodos qualitativos e quantitativos. No que diz respeito aos tratamentos quantitativos, todas as reportagens sobre segurança e todas as propagandas das revistas foram tabuladas e submetidas à análise de três formas distintas: Análise de Variância (ANOVA), Análise de Correlação e Análise de Séries Temporais. A ANOVA buscou analisar a evolução temporal das propagandas e reportagens sobre segurança entre as décadas. A Análise de Correlação visou observar a existência de relação significativa entre propagandas e reportagens sobre segurança.

Por fim, a Análise de Séries Temporais teve por objetivo discriminar o comportamento das variáveis Percentual de Propagandas sobre Segurança e Reportagens sobre Segurança ao longo das décadas, com enfoque em identificar a existência de relações entre elas. Posteriormente, foram comparados os valores de Percentual de Propagandas sobre Segurança com seus próprios valores. Foi executada a regressão básica expressa pela equação (1), onde $n_{i}$ indica o tamanho de cada amostra $i, \bar{x}_{\imath}$ é a média obtida na amostra $i$ e $\bar{x}$ é a média geral de todos os grupos.

$S Q T=\sum_{i=1}^{k} n_{i}\left(\overline{x_{\imath}}-\bar{x}\right)^{2}$

O tratamento qualitativo dos dados, por sua vez, foi destinado às propagandas relacionadas com segurança, que foram analisadas com base nos preceitos de Bardin (1977) e Franco (2005) acerca da Análise de Conteúdo (AC). Bardin (1977) define a AC como um conjunto de técnicas de análise que envolve a utilização de procedimentos sistemáticos e objetivos de descrição do conteúdo das mensagens, evidenciando indicadores que permitem compreendê-las.

A partir da AC, foi possível agrupar os dados em categorias e subcategorias. De acordo com Franco (2005), a elaboração das categorias de análise é o ponto 


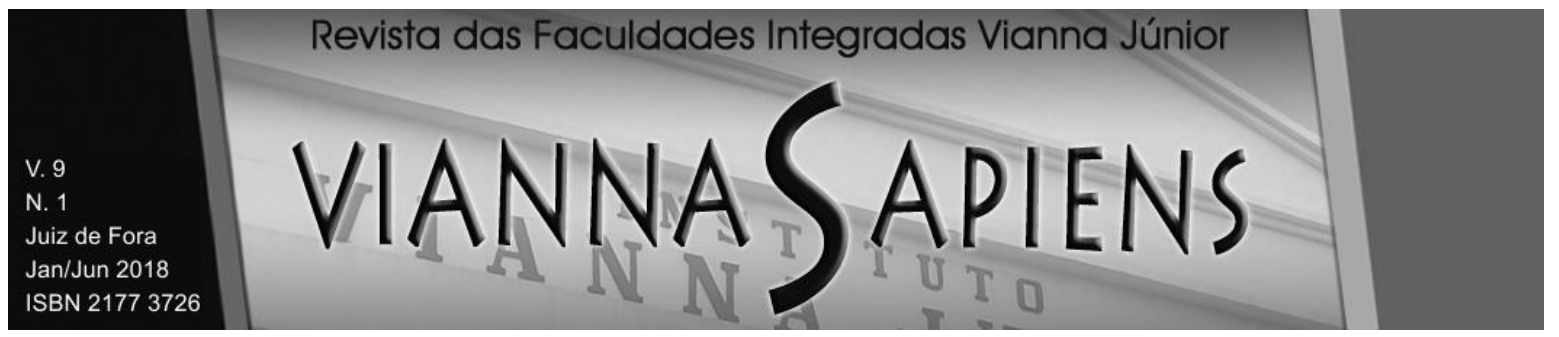

crucial da AC, exigindo grandes esforços por parte do pesquisador em um processo longo, difícil e desafiante.

De acordo com Laville e Dionne (1999), são três os modelos de definição de categorias: aberto, fechado e misto. No modelo aberto as categorias e subcategorias tomam forma durante o processo de análise, não sendo definidas antes do início da pesquisa. O modelo fechado é o contrário: a categorização é definida a priori, antes do início da pesquisa, embasada nos conhecimentos do pesquisador. O modelo misto, utilizado nesta pesquisa, é formado pela junção dos outros dois. As categorias e subcategorias são definidas antes do início da pesquisa, e, após contato com os dados, aperfeiçoadas.

A categorização definida a priori é ilustrada no Quadro 04.

Quadro 04 - Categorias de Análise definidas a priori.

\begin{tabular}{|l|l|}
\hline $\mathbf{1}$ & \multicolumn{1}{|c|}{ CONTEÚDO DA MENSAGEM } \\
\hline 1.1 & Deselo Racional \\
\hline 1.2 & Qualidade \\
\hline 1.3 & Valor \\
\hline $\mathbf{2}$ & Apelo Emocional \\
\hline 2.1 & Afeto \\
\hline 2.2 & Culpa \\
\hline 2.3 & Humor \\
\hline 2.4 & Medo \\
\hline 2.5 & Vergonha \\
\hline $\mathbf{3}$ & Apelo Moral \\
\hline & \\
\hline $\mathbf{4}$ & Conclusão do Anúncio \\
\hline 4.1 & Conteúdo auto-explicativo \\
\hline 4.2 & Conteúdo deixa margem para que o receptor chegue à própria conclusão \\
\hline $\mathbf{5}$ & Tipo de Argumentação \\
\hline 5.1 & Argumentos unilaterais \\
\hline 5.2 & Argumentos bilaterais \\
\hline & \multicolumn{2}{|c|}{} \\
\hline $\mathbf{6}$ & Layout Utilizado \\
\hline 6.1 & Predominância de imagens \\
\hline 6.2 & Predominância de texto \\
\hline 6.3 & Imagens e texto compondo a mensagem principal \\
\hline Fon
\end{tabular}

Fonte: Elaborado pelos autores com base em Kotler e Armstrong (2007).

Com o auxílio do software Atlas.TI, foi aferida a frequência de aparição de cada palavra e, com isso, modificações puderam ser feitas nas categorias definidas 


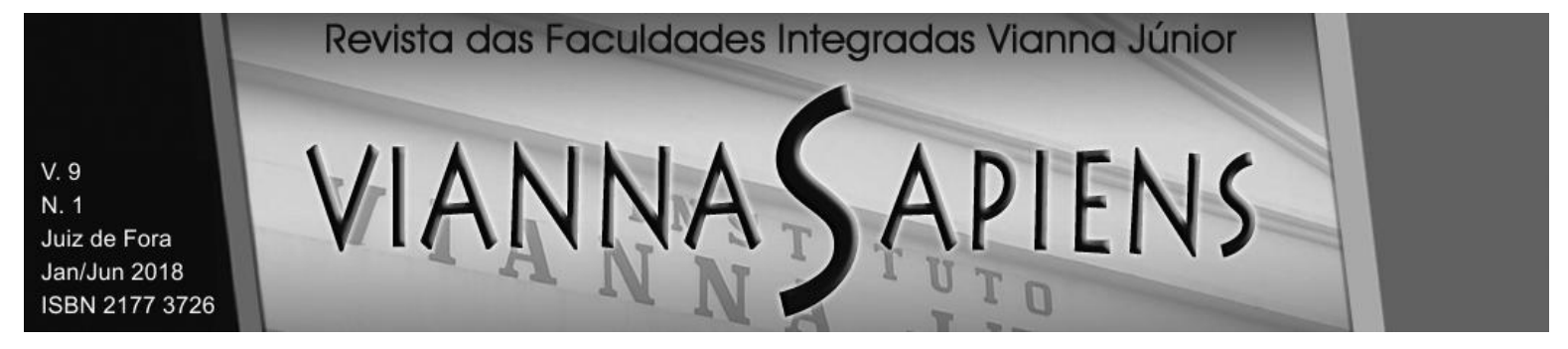

a priori a fim de aperfeiçoá-las. Posteriormente também foram aferidas as frequências de aparição de cada categoria e subcategoria ao longo das décadas de circulação da revista.

\section{ANÁLISE E DISCUSSÃO DOS RESULTADOS}

\subsection{ANOVA, Correlação e Séries Temporais}

A Análise de Variância - ANOVA - indicou que o número médio de reportagens sobre segurança por edição da revista Quatro Rodas apresentou mudança significativa somente entre as décadas de 1960 e 1970, como é possível observar no Gráfico 01 a seguir.

Gráfico 01 - Número médio de Reportagens sobre Segurança por revista, a cada década.

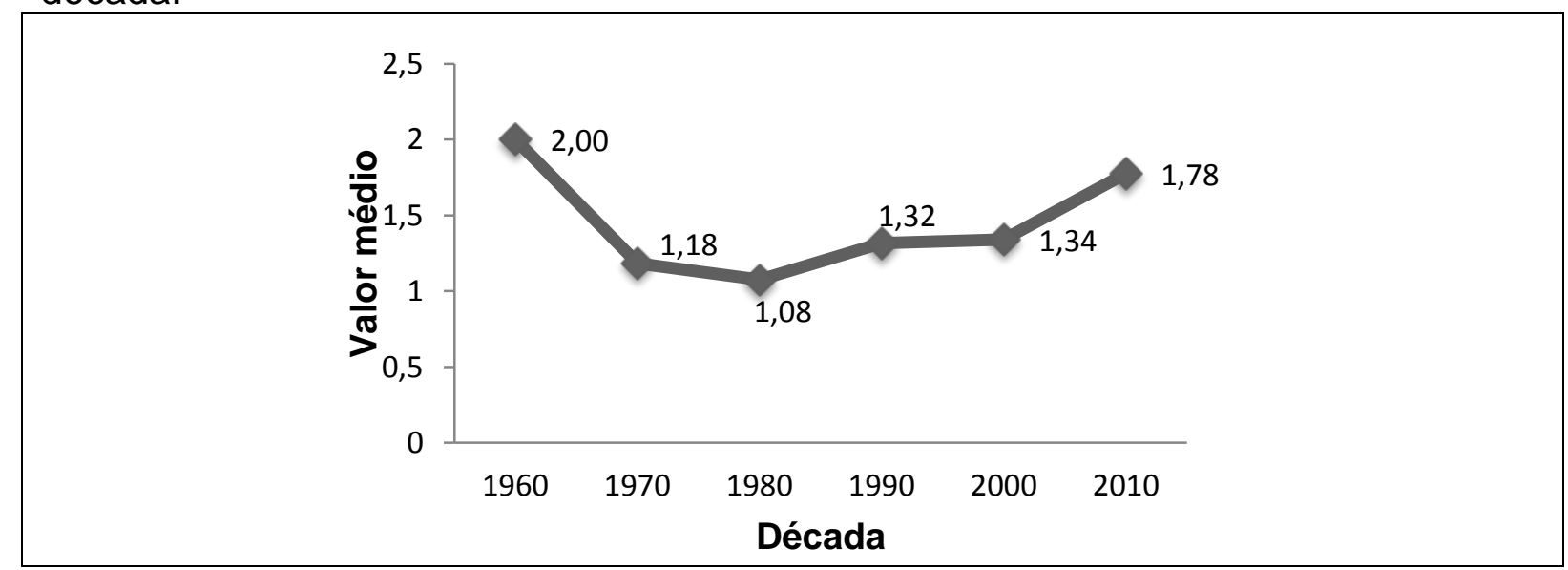

Fonte: Dados da Pesquisa.

Pode-se perceber que a maior média alcançada pelas RS por edição se deu na década de 1960. Em se tratando da primeira década de circulação, possivelmente a revista Quatro Rodas teve intuito de demonstrar a importância dada à segurança automotiva (desde a primeira edição publicada). Observando o comportamento entre as décadas de 1960, 1970 e 1980, pode-se perceber a queda 


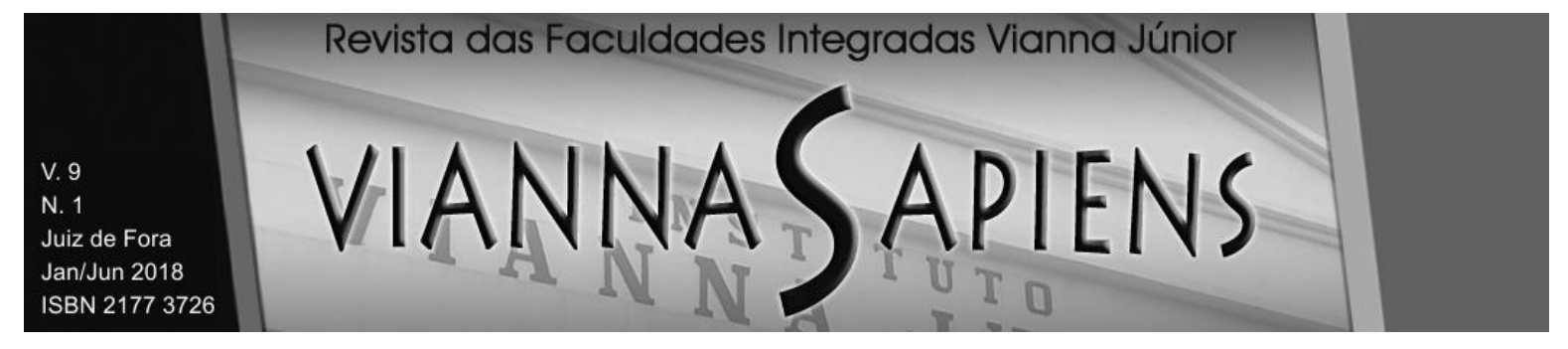

nas médias de RS por edição. Fatores históricos/políticos/econômicos podem ter influenciado neste comportamento, como por exemplo, a crise do petróleo em 1973, alternado 0 assunto das reportagens (não que o assunto central da revista fosse segurança automotiva). A partir de 1980 houve crescimento nas médias de RS por edição/década, traduzindo a importância dada ao tema pela revista nas últimas décadas.

No que diz respeito ao número médio de propagandas sobre segurança, por edição, o Gráfico 02 a seguir indica um aumento significativo do mesmo, entre as décadas de 1960 e 1970, em como uma redução significativa entre as décadas de 1980 e 1990.

Gráfico 02 - Média de Propagandas sobre Segurança por edição, a cada década.

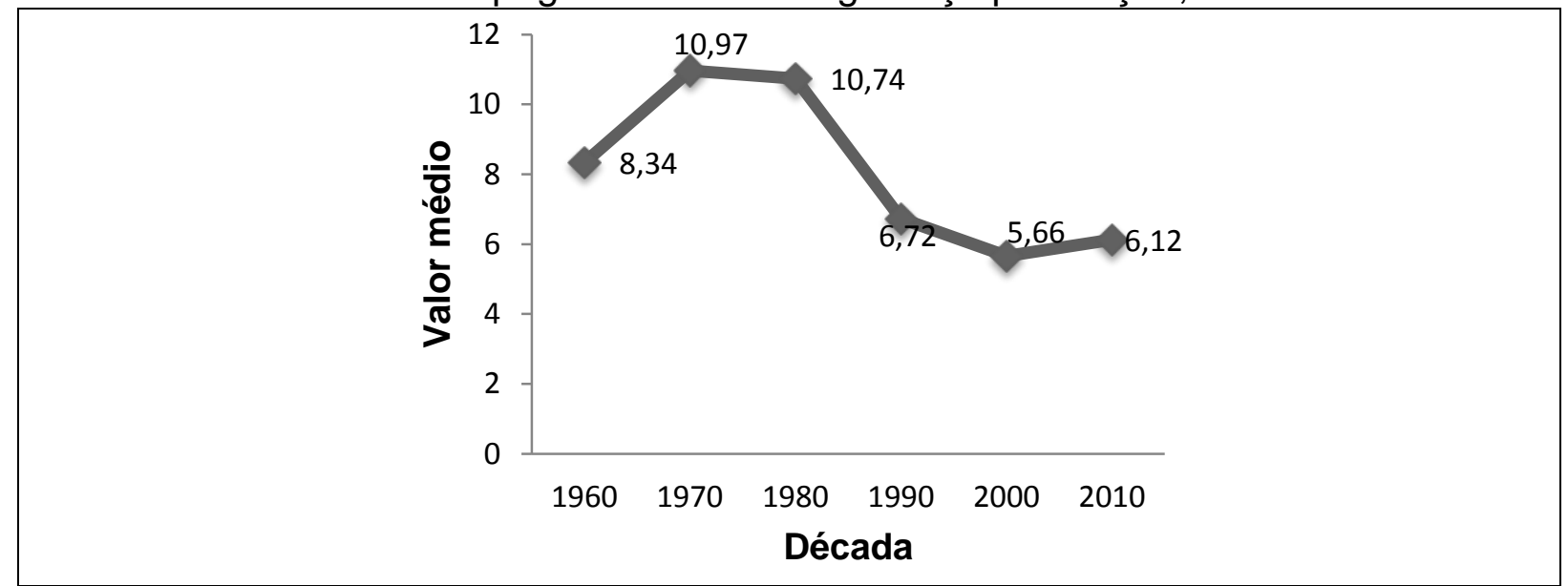

Fonte: Dados da Pesquisa.

Observando o comportamento dos dados dispostos no Gráfico 02 de maneira isolada, tem-se uma falsa ideia da atuação das Propagandas sobre Segurança ao longo das décadas de circulação do periódico, uma vez que este gráfico leva em conta o número absoluto de PS por edição/década, e não o percentual das mesmas sobre o total de propagandas/edição/década. Diante do exposto, ressalta-se a importância da terceira variável considerada: Percentual de Propagandas sobre Segurança (PPS). O Gráfico 03, a seguir, exibe o valor médio desta variável por década. 


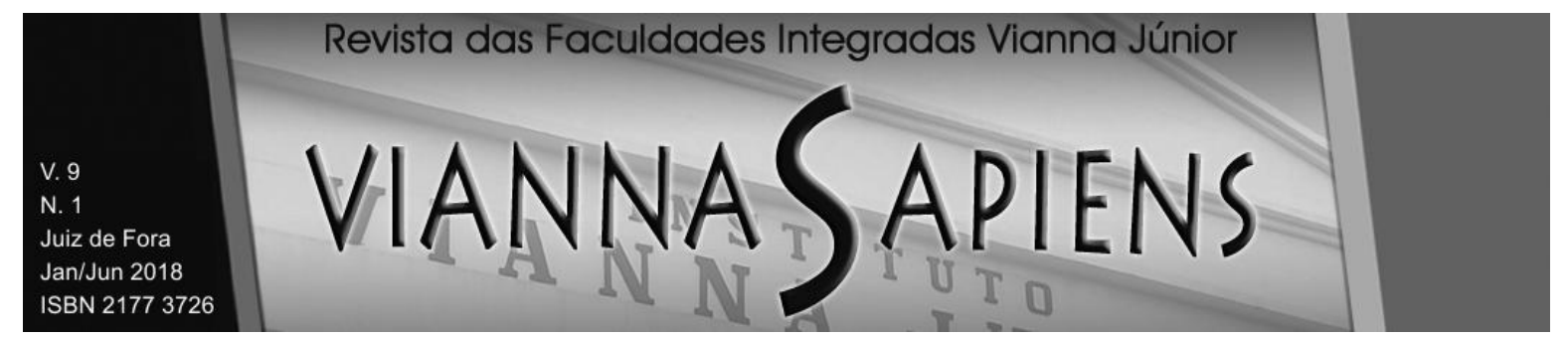

Gráfico 03 - Valor médio do percentual de propagandas sobre segurança, a cada década.

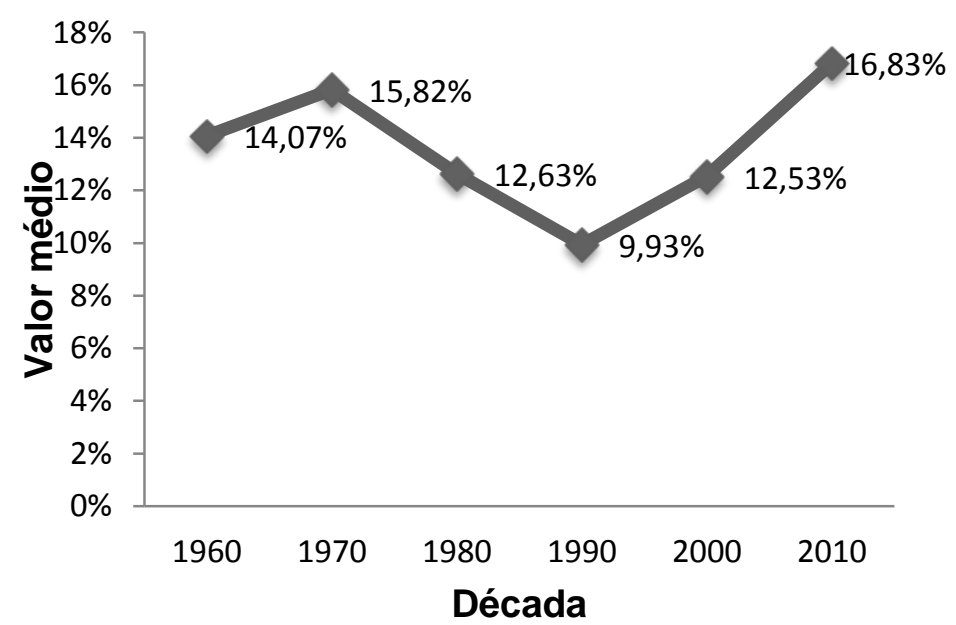

Fonte: Dados da Pesquisa

Analisando os dados ilustrados nos Gráficos 02 e 03 de maneira conjunta, pode-se perceber que, apesar do comportamento semelhante quanto aos declínios e ascensões, a variável PPS retrata de maneira mais completa a realidade da revista Quatro Rodas, posto que, por exemplo, as primeiras edições da revista Quatro Rodas possuíam mais páginas e, consequentemente, possuíam mais propagandas por edição, inclusive havia um número maior de propagandas sobre segurança por periódico. Já as edições mais recentes contam com menos páginas, consequentemente possuindo menos propagandas por edição, inclusive com menos propagandas sobre segurança.

Observando os pontos dispostos no Gráfico 03, pode-se concluir que a frequência relativa de propagandas sobre segurança nunca foi tão elevada como na década mais recente de circulação da revista (2010).

A ANOVA revelou os aumentos significativos dos valores médios entre as décadas de 1990, 2000 e 2010. O mesmo movimento não é observado pelo comportamento de RS, o que indica a possibilidade da não correlação entre as variáveis. 


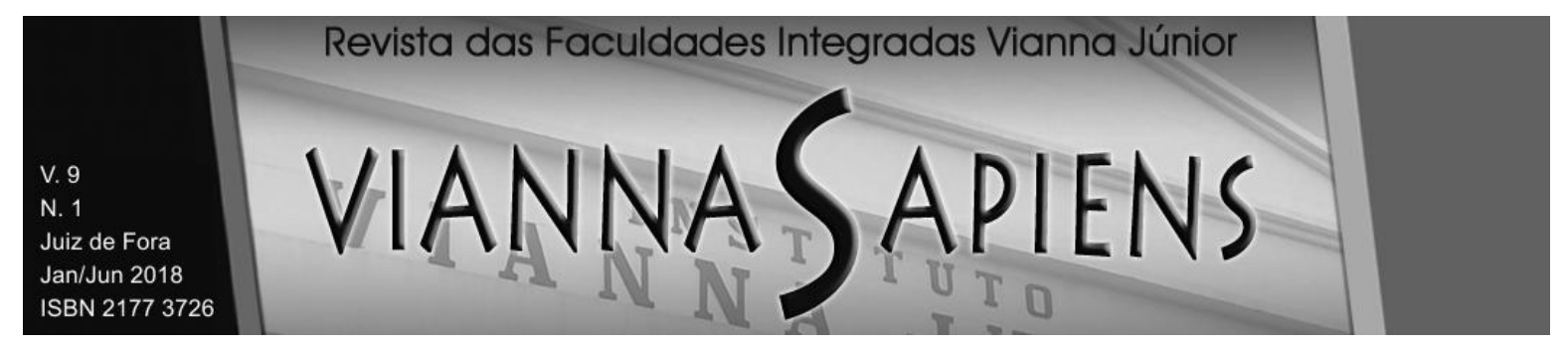

Tal possibilidade foi corroborada pelo teste de correlação, que não encontrou evidências de correlação entre RS e PS $(p=0,524)$, bem como entre RS e PPS $(p=0,761)$.

Por fim, a Análise de Séries Temporais, apesar do nível de ajuste abaixo do esperado, apresentou indícios de autocorrelação positiva, como é possível identificar na Tabela 01.

Tabela 01 - Resultados da Regressão Linear das séries temporais PPS e RS, pelo método de Mínimos Quadrados Ordinários.

\begin{tabular}{lcccc}
\multicolumn{1}{c}{ Variável } & Coeficiente & Erro-padrão & Estatística t & p-valor \\
\hline $\mathrm{C}$ & 0,131989 & 0,003358 & 39,30010 & 0,0000 \\
$\mathrm{RS}$ & 0,000558 & 0,001856 & 0,300816 & 0,7637 \\
\hline $\begin{array}{l}\text { Variável } \\
\text { PPS }\end{array}$ & Estatística F: 0,090490 & Akaike: $-3,003612$ & Schwarz: \\
\hline $\mathrm{R}^{2}: 0,000140$ & p-valor (F): 0,7637 & $\mathrm{n}=648$ & 2,998256 \\
\hline $\mathrm{R}^{2}$ ajustado: $-0,001408$ & Estatística Durbin Watson: 1,129048 & \\
\hline \multicolumn{4}{l}{ Fonte: Dados da Pesquisa. }
\end{tabular}

A fim de confirmar a existência de autocorrelação, exposta pela Tabela 01, foi realizado o teste de autocorrelação de Breusch-Godfrey (BG), que comprovou a existência de uma relação significativa entre o termo de erro e seus valores defasados no tempo, com três edições de defasagem $(p \leq 0,000)$.

Detectada a presença de autocorrelação, foi realizado 0 teste de estacionariedade mais adequado (Dickey-Fulley Aumentado - ADF), cujo resultado indicou que tanto a série $R S(t=-6,101 ; p \leq 0,000)$ quanto a série PPS $(t=-8,306$; $\mathrm{p} \leq 0,000)$ são séries estacionárias. A partir dessa detecção, pode-se iniciar a próxima etapa, envolvendo a investigação da modelação adequada das séries.

A definição da modelagem das séries temporais utilizando a metodologia BoxJenkins teve início com a análise dos correlogramas da série PPS, ilustrado na Figura 01. 


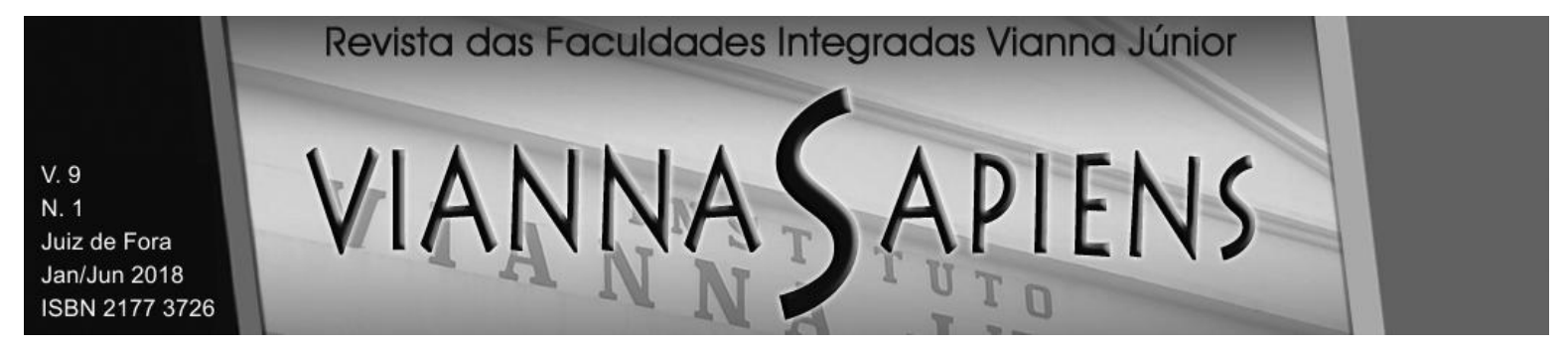

Figura 01: Correlograma da série temporal Percentual de Propagandas sobre Segurança (PPS).

\begin{tabular}{|l|l|}
\hline Autocorrelação & Correlação Parcial \\
\hline & PPS \\
\hline
\end{tabular}

Fonte: Dados da Pesquisa.

Observando o comportamento das variáveis quando da análise dos correlogramas, percebe-se que a variável PPS apresenta características de um modelo auto-regressivo de ordem 3 - AR(3), confirmando a defasagem encontrada no teste BG. A Tabela 02, a seguir, exibe os resultados da Análise de Séries Temporais, levando-se em conta a nova estrutura do modelo.

Tabela 02 - Regressão Linear da série temporal PPS, pelo método de Mínimos Quadrados Ordinários

\begin{tabular}{ccccc}
\hline Variável & Coeficiente & Erro-padrão & Estatística t & p-valor \\
\hline AR(1) & 0,370973 & 0,038630 & 9,603298 & 0,0000 \\
AR(2) & 0,387768 & 0,037847 & 10,24576 & 0,0000 \\
AR(3) & 0,207644 & 0,037876 & 5,482195 & 0,0000 \\
\hline Variável Dependente: PPS & $\mathrm{n}=645$ & Akaike: -3,275296 & Schwarz: -3,267230 \\
$\mathrm{R}^{2}: 0,208499$ & Convergência após 3 iterações & Raízes Inv. AR: ,98 &,$- 31-, 34 \mathrm{i}$ &,$- 31+, 34 \mathrm{i}$ \\
\hline $\mathrm{R}^{2}$ ajustado: 0,206033 & Estatística Durbin Watson: 2,044470 & & \\
\hline
\end{tabular}

Fonte: Dados da Pesquisa.

Os resultados expostos na Tabela 02 indicam que PPS é afetado por PPS referente a até três períodos anteriores. Pode-se explicar tal fenômeno pelo fato de 


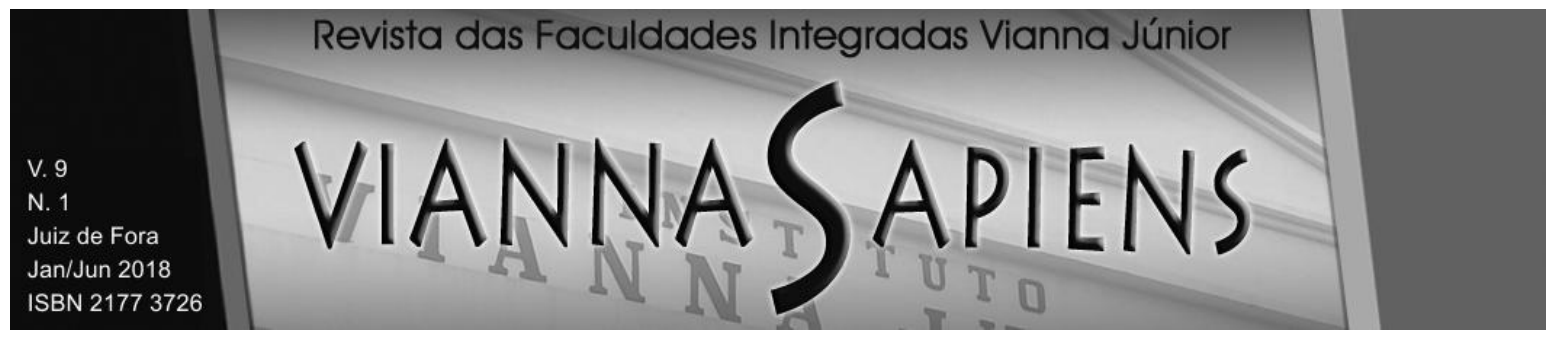

as empresas, geralmente, optarem por elaborar campanhas publicitárias objetivando publicações em mais de uma edição da revista, contribuindo, desta forma, com o componente inercial da variável PPS.

\subsection{Análise de Conteúdo - AC}

As categorias nas quais as palavras foram agrupadas (definidas após contato aprofundado com os dados) estão dispostas no Quadro 05.

Quadro 05 - Categorias finais de Análise.

\begin{tabular}{|l|l|}
\hline 1 & \multicolumn{1}{|c|}{ TIPOS DE SEGURANÇA } \\
\hline 1.1 & Estrutura do Veículo \\
\hline 1.2 & Itens de Segurança Interna \\
\hline 1.3 & Lâmpadas e Faróis \\
\hline 1.4 & Manutenção \\
\hline 1.5 & Para-brisas, vidros, retrovisores \\
\hline 1.6 & Pneus, freios, suspensão e estabilidade \\
\hline 2 & \multicolumn{1}{|c|}{ FOCO DO ANÚNCIO } \\
\hline 2.1 & Cliente ou Terceiros \\
\hline 2.1 .1 & Cliente \\
\hline 2.1 .2 & Terceiros \\
\hline 2.2 & Sensações Proporcionadas \\
\hline 2.2 .1 & Alerta \\
\hline 2.2 .2 & Convencimento \\
\hline 2.2 .3 & Culpa e Vergonha \\
\hline 2.2 .4 & Medo \\
\hline 2.2 .5 & Proteção \\
\hline 2.2 .6 & Tranquilidade \\
\hline 3 & \\
\hline 3.1 & Tipo de Veículo \\
\hline 3.1 .1 & Motocicletas e Afins \\
\hline 3.1 .2 & Pick-ups, caminhonetes, utilitários e SUVs \\
\hline 3.1 .3 & Veículos de Grande Porte \\
\hline 3.1 .4 & Veículos de Passeio \\
\hline 3.2 & "Acompanhantes" da Segurança \\
\hline 3.2 .1 & Beleza \\
\hline 3.2 .2 & Conforto \\
\hline 3.2 .3 & Desempenho \\
\hline 3.2 .4 & Economia/Eficiência \\
\hline 3.2 .5 & Qualidade \\
\hline 3.2 .6 & Tecnologia \\
\hline
\end{tabular}

Fonte: Elaborado pelos autores. 


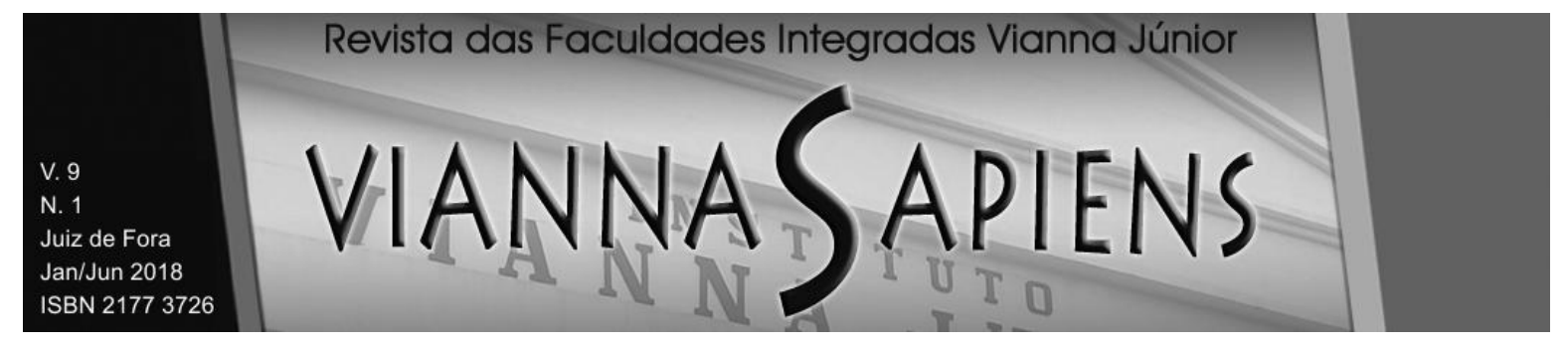

Findado o processo de criação das categorias de análise, as palavras dispostas em todas as propagandas relacionadas à segurança automotiva foram agrupadas nas respectivas categorias com o auxílio do software Atlas.TI. A partir do agrupamento, pôde-se aferir as frequências de aparição de cada categoria por década.

As análises feitas a partir das subcategorias agrupadas quanto aos "tipos de segurança" resultaram no Gráfico 04.

Gráfico 04 - Tipos de Segurança

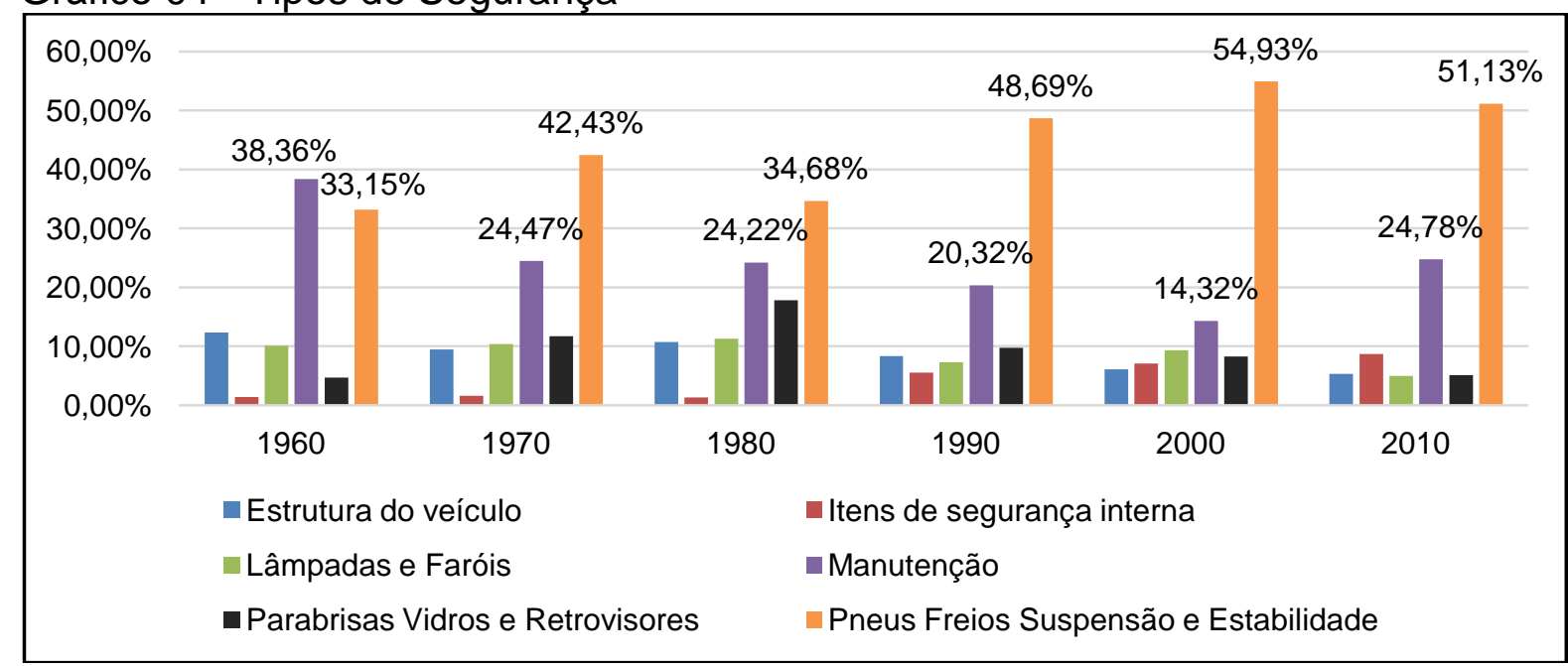

Fonte: Dados da Pesquisa.

Nota-se, observando os dados dispostos no Gráfico 04, que dentre as subcategorias de anúncio consideradas quanto aos tipos de segurança, "pneus, freios, suspensão e estabilidade" e "manutenção" obtiveram as maiores frequências de aparição em todas as décadas de circulação da revista. Possivelmente, os métodos de comunicação relacionados às duas categorias sofreram alterações ao longo das décadas, porém, pode-se perceber a importância dada pelos anunciantes aos anúncios relacionados às duas categorias.

Os esforços das marcas para fidelizar clientes estimulando a reposição de peças e reforçando a importância da realização de serviços em estabelecimentos com profissionais especializados podem estar atrelados à alta frequência de 


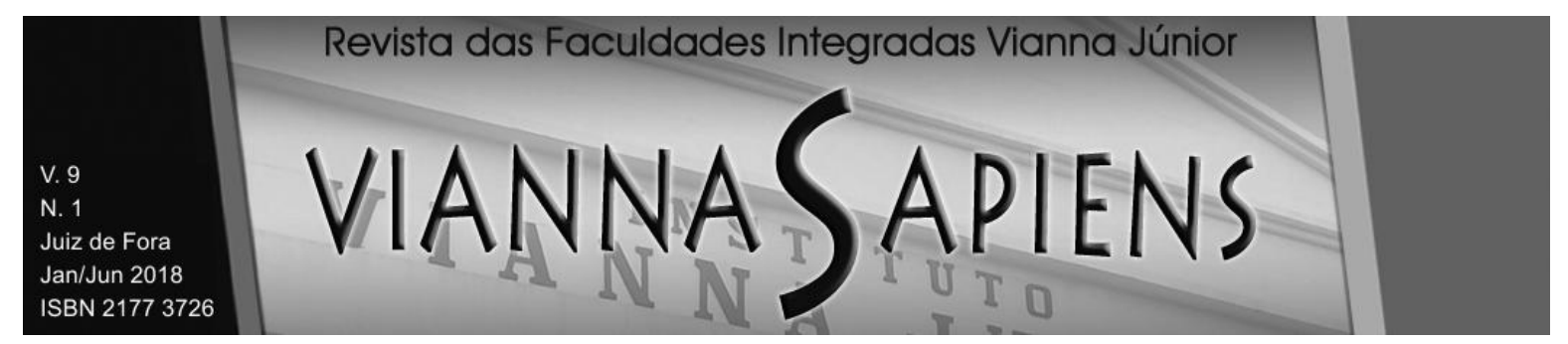

aparição da subcategoria "manutenção". A subcategoria "pneus, freios, suspensão e estabilidade" e sua alta frequência de aparição em todas as décadas pode estar ligada ao envolvimento de produtos e sistemas com necessidade de apresentar bom estado de conservação, essenciais a todo automóvel como método de prevenção de riscos, além de existirem diversas marcas concorrentes disputando a preferência dos consumidores.

A subcategoria "estrutura dos veículos" somente não apresentou comportamento descendente entre as décadas de 1970 e 1980, possuindo, em 2010, a menor frequência de aparição, se comparada às demais. Tal comportamento pode estar relacionado à outra subcategoria analisada: "itens de segurança interna", que será comentado a seguir.

Os anúncios relacionados aos "itens de segurança interna" somente não apresentaram comportamento ascendente entre as décadas de 1970 e 1980, possuindo, em 2010, a maior frequência de aparição se comparada às demais. As exigências legais por parte das agências reguladoras com relação à segurança envolvem tanto a estrutura dos veículos quanto seus itens de segurança interna, mas, ao analisar o comportamento dos anúncios ilustrados na Gráfico 04, percebese que as propagandas parecem direcionar seus esforços à exposição das modificações nos automóveis relacionadas aos itens de segurança interna.

A subcategoria "lâmpadas e faróis" apresentou comportamentos distintos entre as seis décadas, sendo que entre 1960, 1970 e 1980 houve aumento na frequência de aparição, entre 1980 e 1990 houve redução, entre 1990 e 2000 aumento e, de 2000 a 2010, houve redução novamente. Nas primeiras décadas de circulação das revistas, anúncios voltados à educação para o trânsito e de empresas anunciando novos produtos ressaltavam a importância da iluminação e visibilidade nos automóveis como garantia de segurança aos ocupantes e demais condutores que viajam em sentido contrário. Percebe-se, nas décadas mais recentes, que há redução na frequência de aparição da subcategoria "lâmpadas e faróis", o que pode traduzir a redução da preocupação com a iluminação dos automóveis por parte dos 


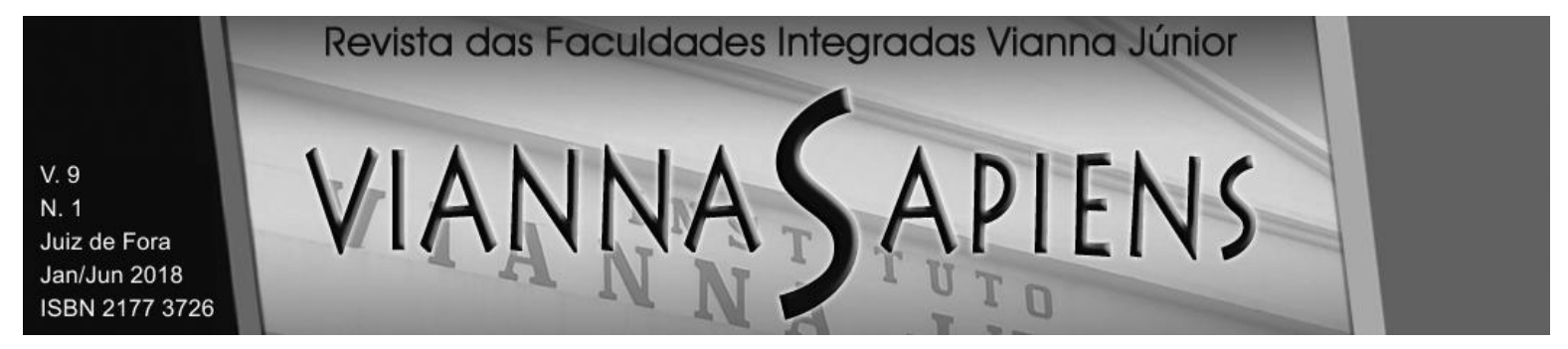

anunciantes, ou, mais provavelmente, que a população (usuários de automóveis) reconheça a importância de equipamentos de iluminação, não necessitando desse tipo de anúncio para disseminar informações quanto à importância de tais equipamentos.

As menores frequências de aparição da subcategoria "para-brisas, vidros e retrovisores" foram obtidas nas décadas de 1960 e 2010. As maiores frequências foram alcançadas em 1970 e 1980, podendo estar relacionadas aos anúncios alertando quanto aos perigos do estilhaçamento dos vidros e suas consequências, bem como anúncios de marcas de películas protetoras de vidros com a promessa de evitar tal fato. A partir da década de 1980, a subcategoria apresentou comportamento descendente em todas as décadas. A explicação para tal comportamento pode estar relacionada à evolução das tecnologias aplicadas aos vidros para evitar estilhaçamentos (prometidos em anúncios de películas), reduzindo o número de ferimentos advindos deste tipo de sinistro, consequentemente reduzindo a publicidade por parte das organizações anunciantes.

Observando o foco dos anúncios (se voltados a clientes ou a terceiros), as análises comparando as subcategorias agrupadas deram origem ao Gráfico 05.

Gráfico 05 - Foco dos Anúncios: Cliente ou Terceiros

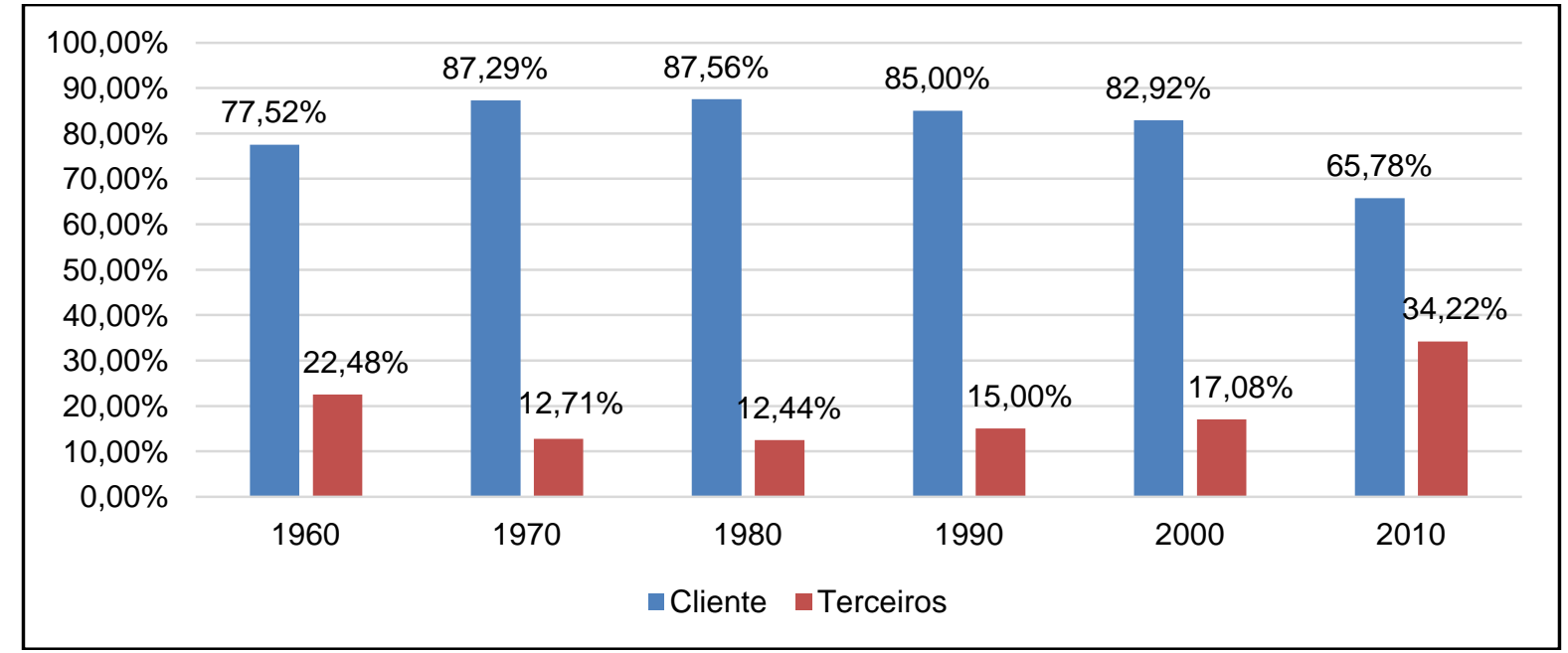

Fonte: Dados da Pesquisa. 


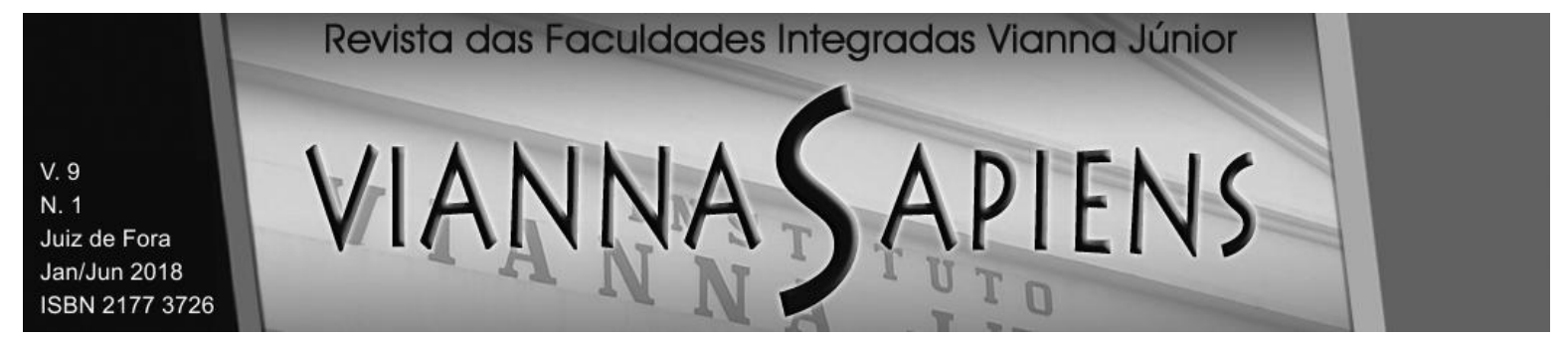

Observando o Gráfico 05, pode-se concluir que desde o início da circulação da revista o principal foco dos anúncios envolve clientes. Porém, pode-se observar também que, a partir da década de 1980, anúncios voltados a clientes apresentam comportamento descendente, enquanto anúncios voltados a terceiros são crescentes. Os anúncios voltados a terceiros podem ter apresentado comportamento crescente devido ao aumento de anúncios afetivos direcionados à família (filhos principalmente) e acompanhantes.

Quanto ao foco dos anúncios (sensações proporcionadas), as análises realizadas a partir das subcategorias agrupadas deram origem ao Gráfico 06.

\section{Gráfico 06 - Foco do Anúncio: Sensações Proporcionadas}

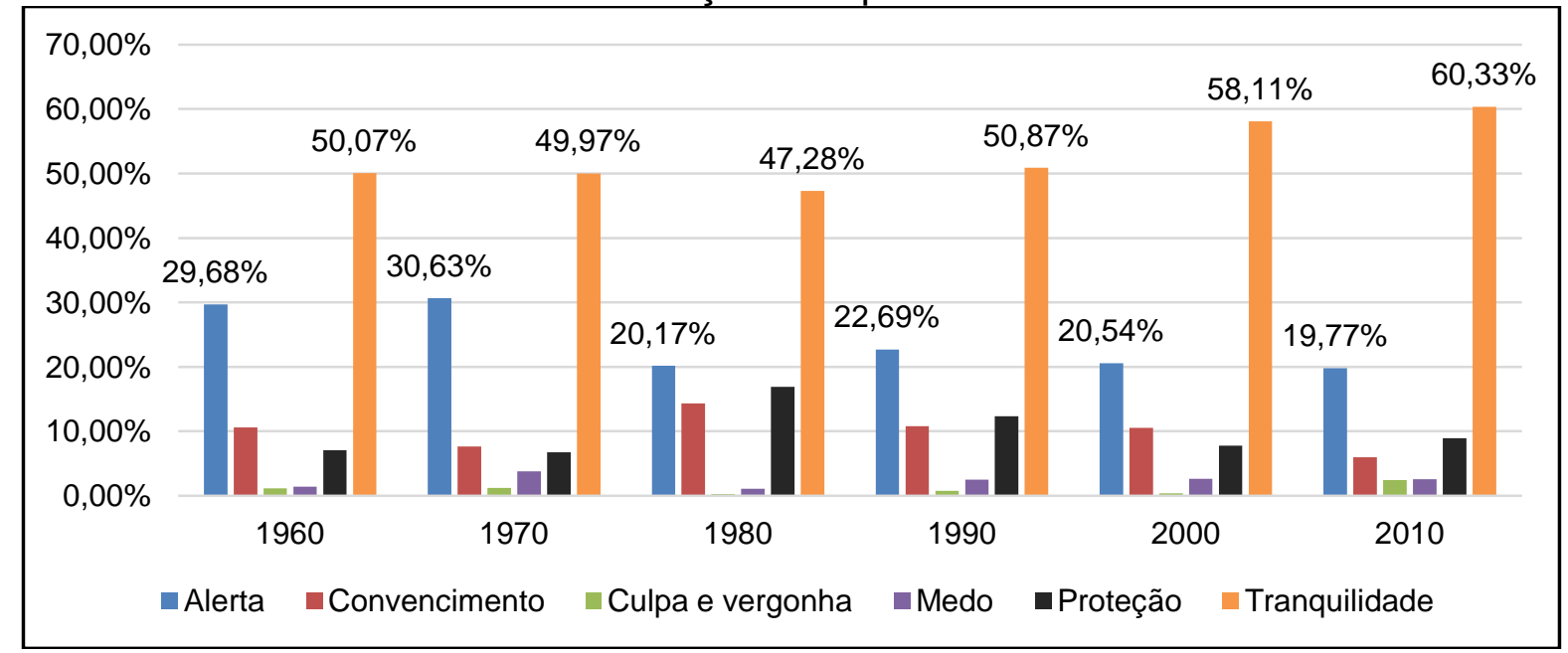

Fonte: Dados da Pesquisa.

A revista Quatro Rodas se utiliza tanto de apelos emocionais positivos (convencimento, proteção e tranquilidade) quanto negativos (alerta, culpa, vergonha e medo) a fim de influenciar os consumidores.

Dentre as subcategorias de anúncio relacionadas às sensações proporcionadas, "alerta" e "tranquilidade" obtiveram as maiores frequências de aparição em todas as décadas. Anúncios que se relacionam à sensação de "tranquilidade" compõem a preferência por parte dos anunciantes para atrair 


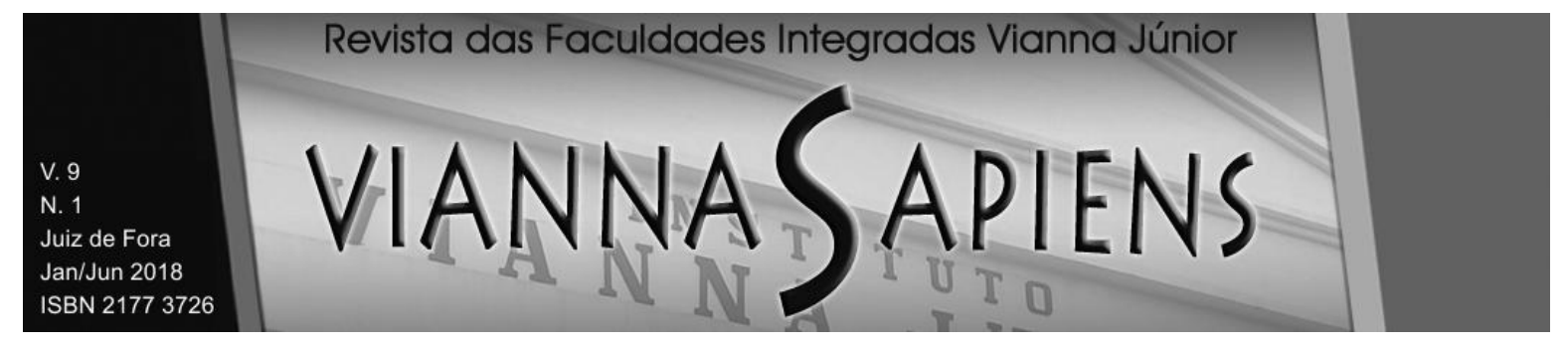

clientes, talvez por acreditarem que tal subcategoria de anúncio resulte em maior aceitação.

"Convencimento" e "proteção" foram as subcategorias que apresentaram as frequências de aparição intermediárias entre as consideradas. As duas obtiveram maior frequência na década de 1980. Desde então, anúncios relacionados ao convencimento apresentaram declínio, enquanto os arremetidos à proteção declinaram entre 1980, 1990 e 2000, aumentando na década de 2010.

De acordo com Lotman (1981), sensações de culpa, medo e vergonha são reguladores sociais. As subcategorias "culpa e vergonha" e "medo" obtiveram as menores frequências de aparição entre as consideradas (apesar de apresentarem as maiores frequências combinadas na última década de circulação da revista 2010), o que sugere que as campanhas envolvendo segurança automotiva não se baseiam nesses reguladores sociais.

Envolvendo as demais informações (tipo de veículo) sobre os anúncios, as análises realizadas considerando as subcategorias agrupadas deram origem ao Gráfico 07.

Gráfico 07 - Demais Informações: Tipo de Veículo

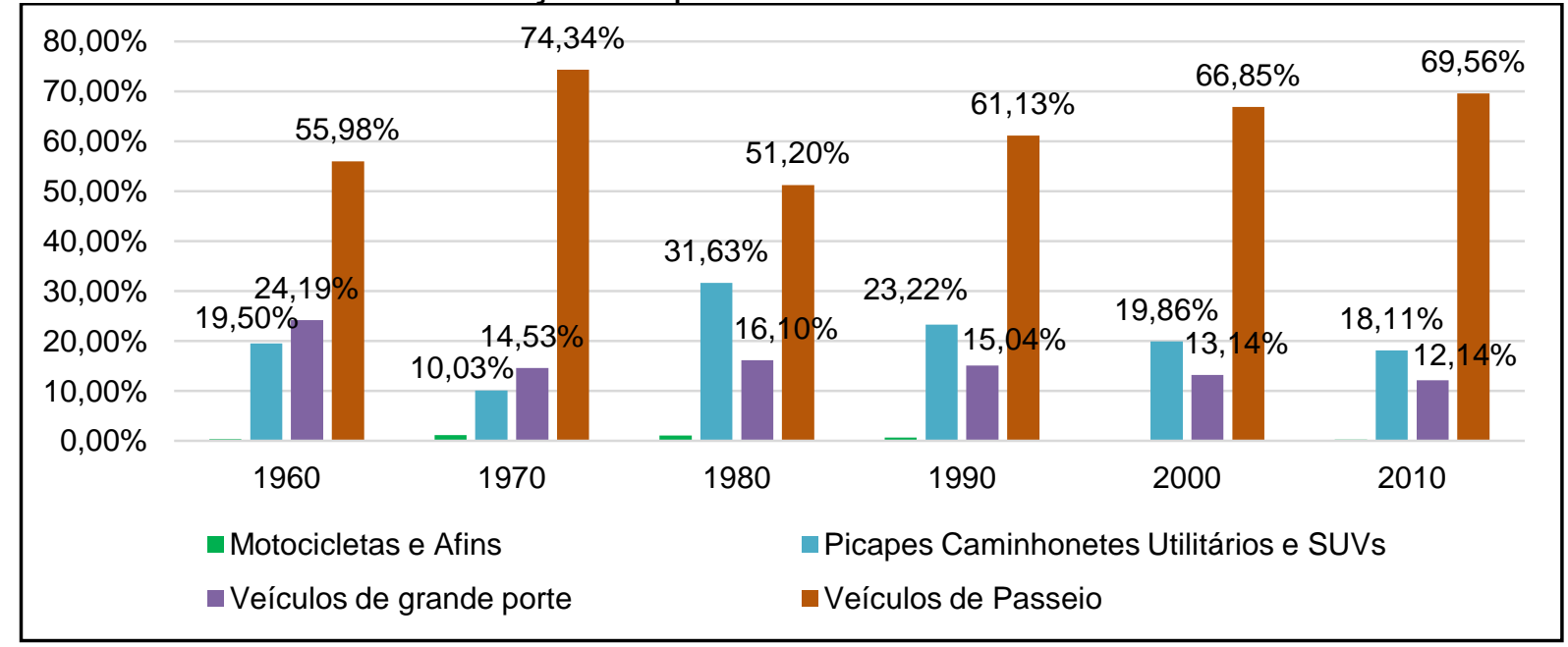

Fonte: Dados da Pesquisa.

Como o nome do periódico sugere, a revista Quatro Rodas publica principalmente anúncios de veículos de passeio. Apesar de existirem outras revistas 


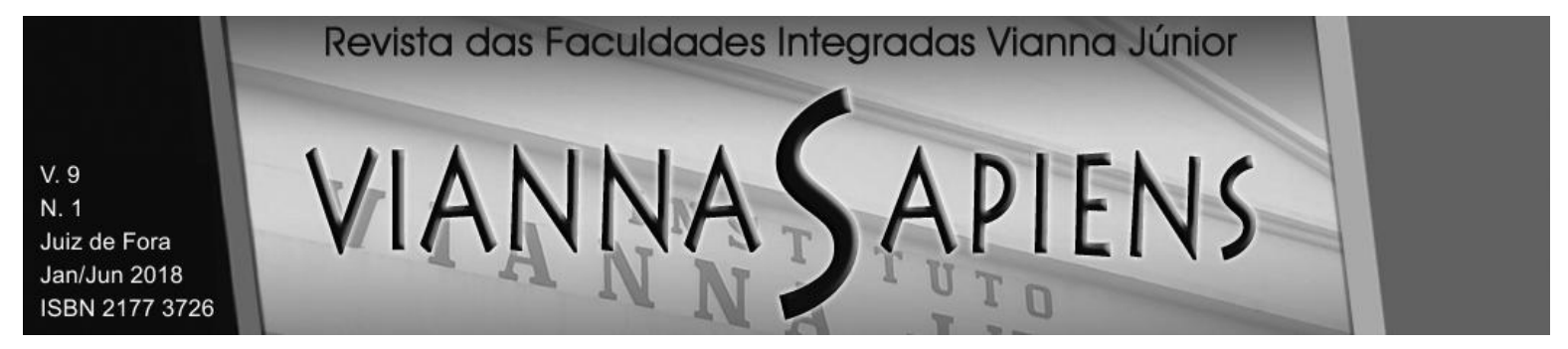

especializadas em outros tipos de veículos em circulação no Brasil, nota-se a presença desses outros tipos de veículos nos anúncios da Quatro Rodas. Propagandas de motocicletas e afins, por exemplo, estão presentes em todas as décadas de circulação da revista (em pequena quantidade).

"Picapes, caminhonetes, utilitários e SUVs" apresentaram expressiva frequência de aparição em todas as décadas, tendo como ponto máximo a década de 1980, desde então apresentando queda.

Anúncios de veículos de grande porte (caminhões, tratores, ônibus e etc.) apareceram com maior frequência em 1960, obtendo, em 2010, sua menor frequência de aparição.

Observando o Gráfico 07 , pode-se concluir que anúncios relacionados a outros tipos de veículos estão em declínio, enquanto anúncios envolvendo veículos de passeio são cada vez mais presentes.

O Gráfico 08 ilustra as análises realizadas com base nas subcategorias agrupadas quanto a demais informações sobre os veículos ("acompanhantes" da segurança).

Gráfico 08 - Demais Informações: "Acompanhantes" da Segurança

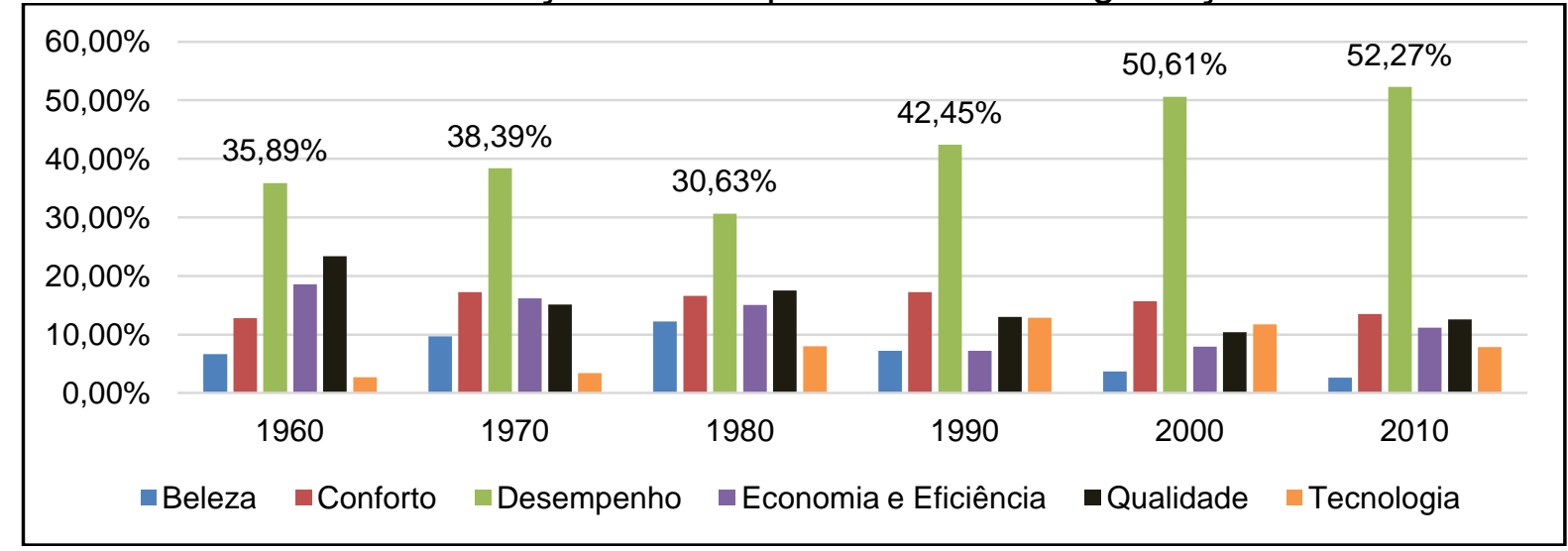

Fonte: Dados da Pesquisa.

Pode-se observar que os anúncios relacionados à segurança automotiva publicados na revista Quatro Rodas se utilizam de apelos racionais para influenciar os consumidores, ligados principalmente aos benefícios que os veículos podem 


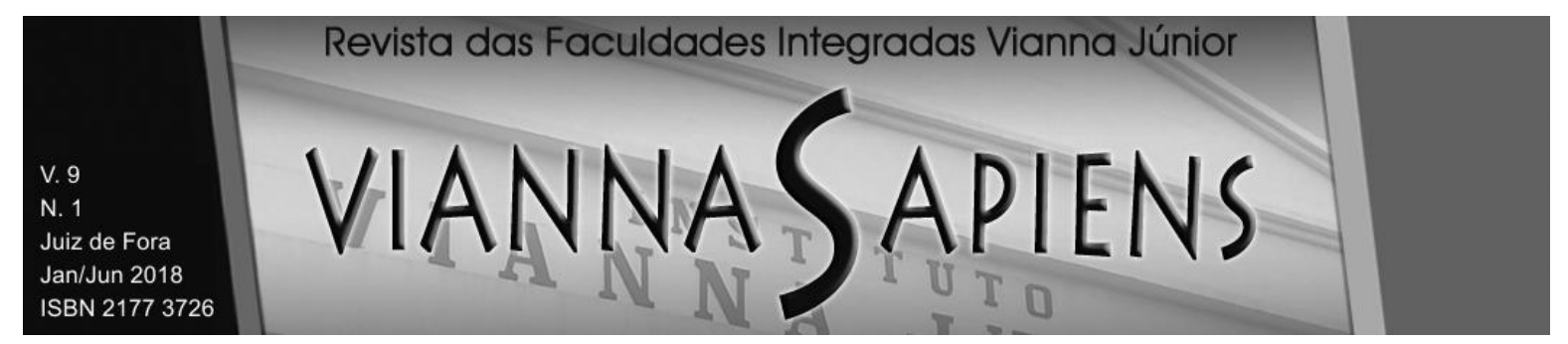

proporcionar (beleza, conforto, desempenho, economia, eficiência, qualidade e tecnologia).

Stevens (2013) afirma que tanto as campanhas publicitárias oriundas do Governo quanto as da Indústria Automotiva possuem apelo voltado aos desejos individuais de liberdade e velocidade, seja em campanhas educativas (visando a prevenção) ou para estimular o consumo. Observando as informações dispostas no Gráfico 08 , nota-se que em todas as décadas a subcategoria com maior frequência de aparição foi "desempenho", com maior índice na última década de circulação da revista. Provavelmente os anunciantes visam conquistar clientes expondo principalmente características dos veículos relacionadas a desempenho e velocidade. Entretanto, cabe ressaltar que desempenho e velocidade são as principais causas dos acidentes de trânsito, estando, portanto na "contramão" da segurança automotiva.

A subcategoria "beleza" apresentou comportamento crescente entre 1960, 1970 e 1980, e, a partir daí, exibiu comportamento decrescente, papel semelhante ao obtido pela subcategoria "tecnologia" (crescente entre as décadas de 1960, 1970, 1980 e 1990, decrescente entre 200 e 2010). As edições mais antigas eram compostas predominantemente por texto (contendo imagens reduzidas), enquanto as mais recentes apresentam predominância de imagens e quantidade reduzida de texto.

Provavelmente "beleza" (facilmente expressa em imagens) e "tecnologia" ainda sejam amplamente propagadas, porém, como se percebe nas frequências de aparição das últimas décadas, não em forma de texto.

A subcategoria "conforto" obteve comportamento pouco oscilante ao longo das décadas, possuindo menores frequências nas décadas de 1960 e 2010. Já a subcategoria "qualidade" apresentou maior frequência de aparição na década de 1960 e menores frequências nas décadas de 2000 e 2010. Como o mercado possui marcas consolidadas e amplamente conhecidas, acredita-se que aspectos como 


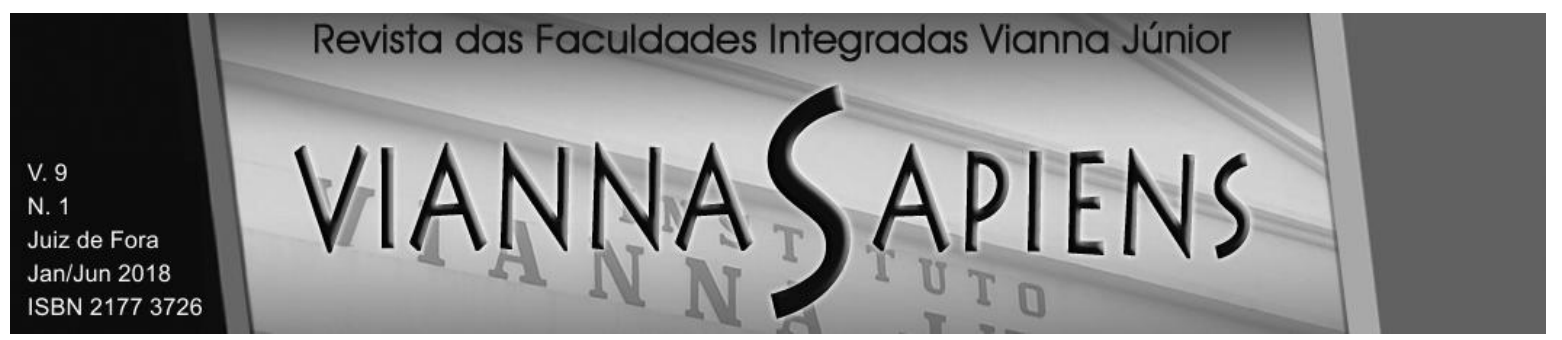

conforto e qualidade, menos presentes em forma de texto, estão presentes de maneira intrínseca, atrelados às marcas.

Por fim, anúncios relacionados à subcategoria "economia e eficiência" apresentaram maior frequência de aparição na década de 1960, possuindo comportamento decrescente até a década de 2000, apresentando variação positiva para a década posterior. Apesar de ser amplamente valorizada pelos consumidores, "economia e eficiência" aparentemente não possui tanta prioridade por parte dos anunciantes no tipo de anúncio que foi analisado nesta pesquisa (vale ressaltar novamente que as análises foram realizadas em anúncios relacionados à segurança automotiva).

\section{CONCLUSÕES}

Cumprindo o primeiro objetivo desta pesquisa, que foi investigar como a segurança automotiva foi abordada em reportagens e propagandas presentes nas 647 edições da revista Quatro Rodas disponibilizadas no acervo digital, identificouse que as propagandas e reportagens associadas ao tema segurança automotiva dispostas nas seis décadas de circulação da revista Quatro Rodas não possuem correlação entre si, de acordo com os testes estatísticos realizados.

Além disso, por meio da realização da Análise de Variância, destacou-se que o percentual de propagandas sobre segurança, por edição, apresenta crescimento significativo desde a década de 1990, indicando a importância deste tema para o consumidor brasileiro. As reportagens sobre segurança não acompanharam este movimento, ou seja, não apresentaram crescimento ao longo das décadas, o que pode indicar a não correlação entre as duas variáveis. Tal evidência traduz, possivelmente, que o tipo de reportagem presente na revista não influencia as opções de anúncios feitas pelos anunciantes. 


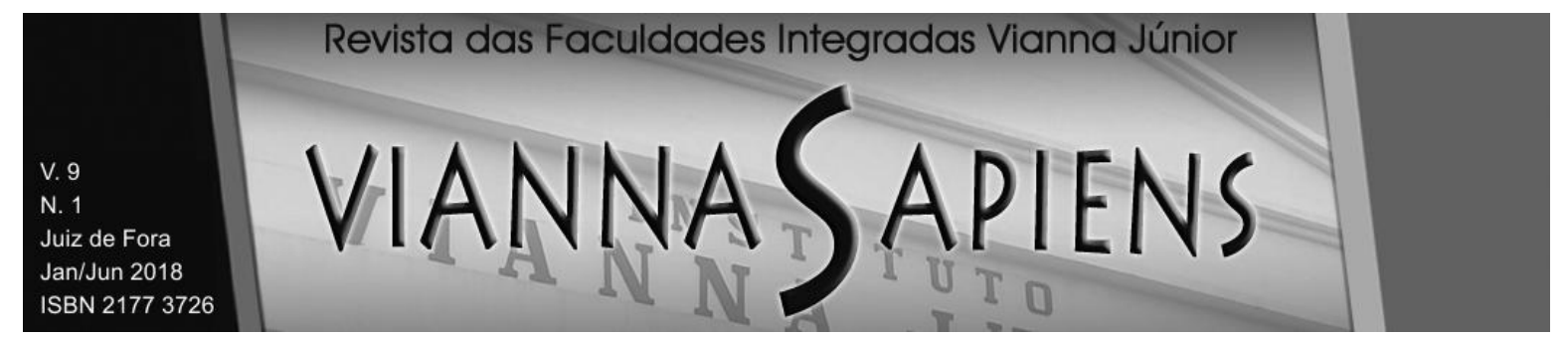

A Análise de Séries Temporais indicou que o percentual de propagandas sobre segurança demonstra um componente auto-regressivo após três iterações, provavelmente provocado pelo efeito inercial das campanhas publicitárias, que geralmente possuem veiculação em mais de uma edição consecutiva.

Quanto ao objetivo de analisar, de maneira mais profunda, como o conteúdo das propagandas sobre segurança automotiva da referida revista evoluiu ao longo do período entre agosto de 1960 e outubro de 2013, as comparações realizadas entre as categorias e subcategorias, criadas a partir das frequências de aparição das palavras presentes em cada anúncio e das percepções dos autores, pôde-se ilustrar o comportamento do conteúdo dos anúncios relacionados ao tema segurança automotiva ao longo das seis décadas de circulação da revista quanto aos tipos de segurança, foco dos anúncios e demais informações sobre os veículos.

Considerando o fato de que as campanhas publicitárias geralmente são desenvolvidas com base em desejos e necessidades dos consumidores (com vistas a explorá-los a fim de estimular o consumo), os resultados alcançados refletem suas preferências e seu comportamento ao longo do período de circulação da revista. A partir dos resultados expostos, as agências publicitárias podem observar 0 comportamento dos anúncios nos últimos anos e, a partir daí, moldar suas campanhas objetivando atrair a atenção e preferências dos consumidores.

Por ter realizado Análise de Conteúdo somente da parte textual, desconsiderando imagens, a pesquisa tornou-se limitada. Como sugestão de pesquisa futura, a fim de aprofundar discussões em casos específicos, sugere-se a aplicação de métodos de análise que considerem e relacionem tanto as imagens quanto texto, tendo como finalidade a produção de conclusões mais robustas. 


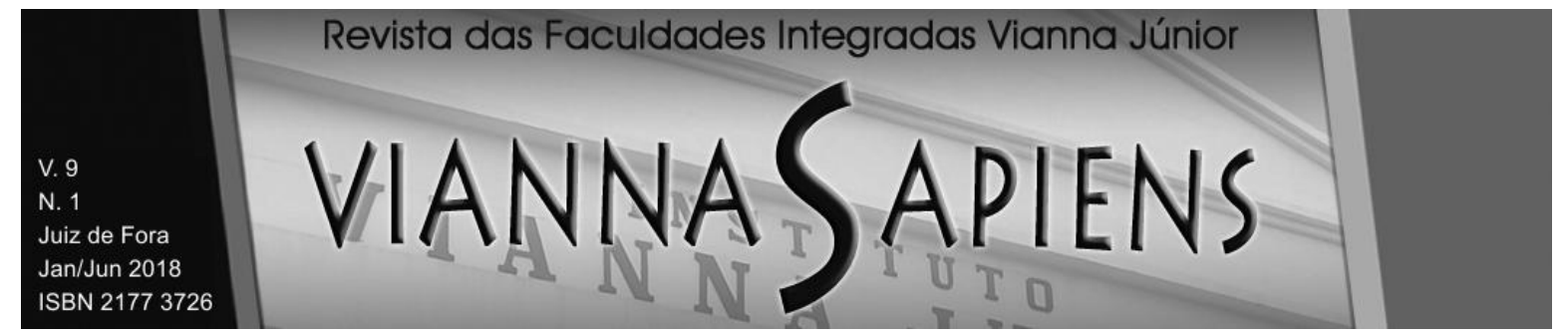

\title{
ANALYSIS OF ADVERTISING AND REPORTS ABOUT AUTOMOTIVE SAFETY PUBLISHED IN QUATRO RODAS MAGAZINE
}

\begin{abstract}
The feeling of insecurity in traffic can be identified by the constant dissemination of reports that trigger it, as well as by the significant presence of advertisements for automotive safety products in various media. This work aimed to analyze the evolution of advertisements and reports about automotive safety in editions of Quatro Rodas magazine, investigating all the 647 online editions available. The research used ANOVA, Time Series Analysis and Content Analysis (CA) to analyze data. Results showed a significant increase in the percentage of advertisements over security since 1990. Reports about safety did not express similar behavior. A significant relationship was identified between the percentage of safety advertisements and their own values, lagged in three editions, evidencing the influence of advertising campaigns during this period. The CA found that ads related to feelings of tranquility and alertness are the most frequent in all decades.
\end{abstract}

KEYWORDS: AUTOMOTIVE SAFETY. CONSUMER BEHAVIOR. CONTENT ANALYSIS. ADVERTISING. REPORTS.

\section{REFERÊNCIAS}

ACEVEDO, C. R.; RAMUSKI, C. L.; NOHARA, J. J.; TRINDADE, L. V. P. A content analysis of the roles portrayed by women in commercials: 1973 - 2008. REMark Revista Brasileira de Marketing, v.9, n.3, p. 170-196. 2010. 


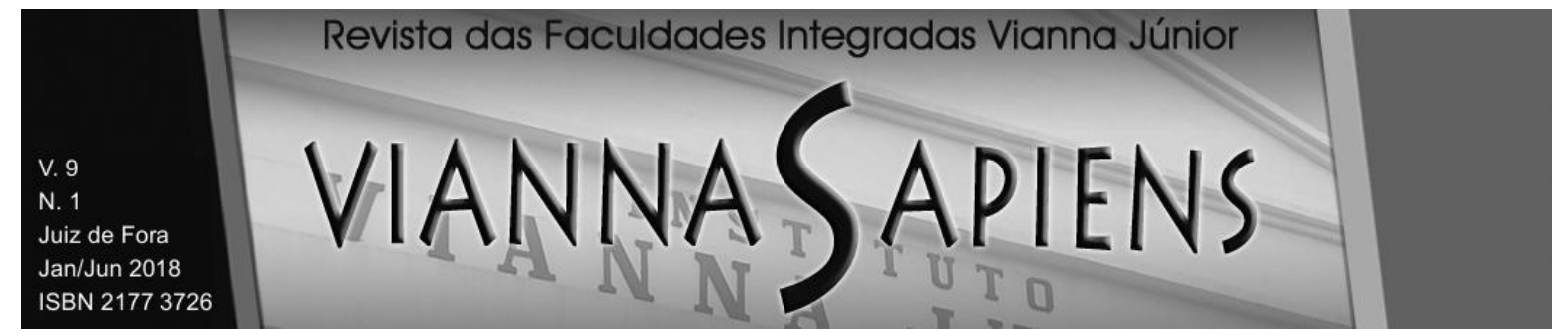

ARAÚJO, M. M.; MALLOY-DINIZ, L. F.; ROCHA, F. L. Impulsividade e acidentes de trânsito. Revista de Psiquiatria Clínica, v.36, n.2, p. 60-68, 2009.

ASSOCIAÇÃO NACIONAL DE EDITORES DE REVISTAS - ANER. Circulação. Revistas Mensais - 2013 × 2014 (Jan a Set). Disponível em:

<http://aner.org.br/dados-de-mercado/circulacao>. 2014. Acesso em 29/04/2016.

BARDIN, L. Análise de conteúdo. Lisboa: Edições 70, 1977.

BAZANINI, R.; ROSSI, G. B.; PLANTULO, V. L. Comunicação em Marketing. Análise das Estratégias Presentes nos Conteúdos das Propagandas de Empresas de Serviços. Um Estudo Descritivo e Proposições de Pesquisa. Revista de Administração da UNIMEP, v.3, n.1, p. 48-72, 2005.

BRASIL. Lei № 11910, de 18 de março de 2009. Altera o art. 105 da Lei $n^{\circ}$ 9.503, de 23 de setembro de 1997. Diário Oficial da União. Brasília, 19 mar. 2009a.

Disponível em: <www.in.gov.br>. Acesso em 29/04/2016.

. Lei № 12006, de 29 de julho de 2009. Acrescenta artigos à Lei no 9.503, de 23 de setembro de 1997. Diário Oficial da União. Brasília, 30 jul. 2009b. Disponível em: <www.in.gov.br>. Acesso em 29/04/2016.

CELINSKI, G. M.; SKURA, I. Mídia impressa, comunicação e história:

breves considerações e aproximações. Temática. n. 6. 2018.

CHERIAN, J. Emergence of Digital Publishing: A Great Challenge to The Print Publications. Procedia Economics and Finance, n. 23, p. 576 - 586, 2015.

COBRA, M. Administração de marketing no Brasil. 3 ed. Rio de Janeiro: Elsevier/Campus, 2009.

CROCCO, L., TELLES, R., GIOIA, R. M., ROCHA, T., STREHLAU, V. I.

Fundamentos de marketing: conceitos básicos. 2 ed. São Paulo: Saraiva, 2010. 


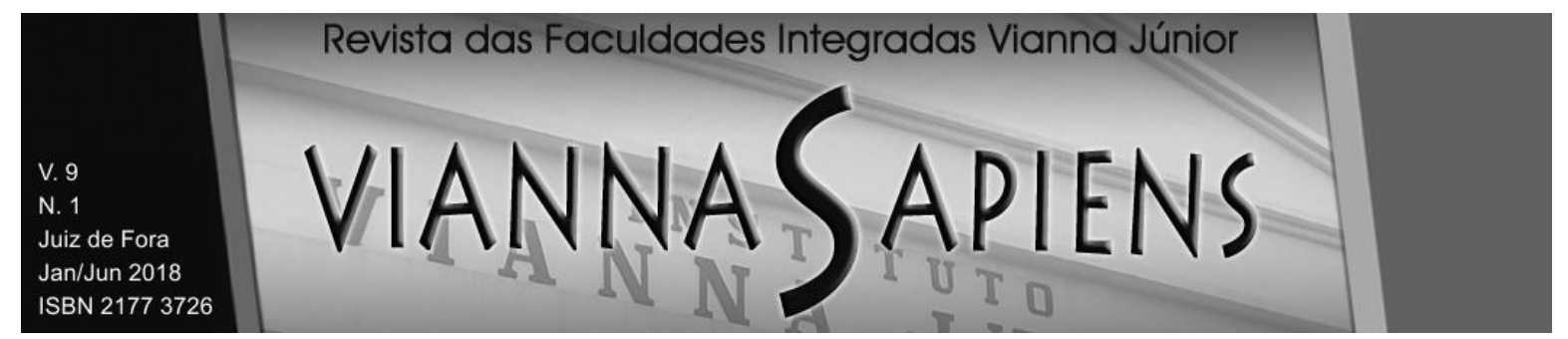

DAMATTA, R. Fé em Deus e pé na tábua: ou como e por que o trânsito enlouquece no Brasil. Rio de Janeiro: Rocco, 2010.

DEARO, G. Os 20 países com mais mortes no trânsito (e os 20 com menos).

Revista Exame (versão digital). 2014. Disponível em:

$<$ https://exame.abril.com.br/mundo/os-20-paises-com-mais-mortes-no-transito-e-os-

20-com-menos/>. Acesso em 29/04/2016.

DICIONÁRIO MICHAELIS. Segurança. Disponível em:

$<$ http://michaelis.uol.com.br/moderno/portugues/index.php?lingua=portugues-

portugues\&palavra=seguran\%E7a>. Acesso em 29/04/2016.

FARIA, S. G. S., NOHARA, J. J., LOPES, E. L., ACEVEDO, C. R., CAMPANARIO, P. M. Uma análise das representações dos afrodescendentes nas propagandas de jornais paulistas. PRETEXTO, v. 15, n.1, p. 62-85, 2014.

FRANCO, M. L. P. B. Análise de Conteúdo. 2 ed. Brasília: Liber Livro, 2005.

GOLD, P. A. Segurança de Trânsito. Aplicações de Engenharia para Reduzir

Acidentes. [S.I.]: Banco Interamericano de Desenvolvimento, 1998.

GONZÁLEZ-LÓPEZ, J. R., RODRÍGUEZ-GÁZQUEZ, M. A., LOMAS-CAMPOS, M. M. Lesões por Acidentes de Trânsito e uso de medidas de segurança por imigrantes latino-americanos residentes em Sevilha. Revista de Enfermagem Referência, v.4, n.3, p. 105-111, 2014.

KOTLER, P., ARMSTRONG, G. Princípios de Marketing. 12 ed. São Paulo: Pearson Prentice Hall, 2007.

LAS CASAS, A. L. Administração de Marketing: Conceitos, planejamento e aplicações à realidade brasileira. São Paulo: Atlas, 2010.

LAVILLE, C. DIONNE, J. A construção do saber: manual de metodologia a pesquisa em ciências humanas. Belo Horizonte: UFMG, 1999. 


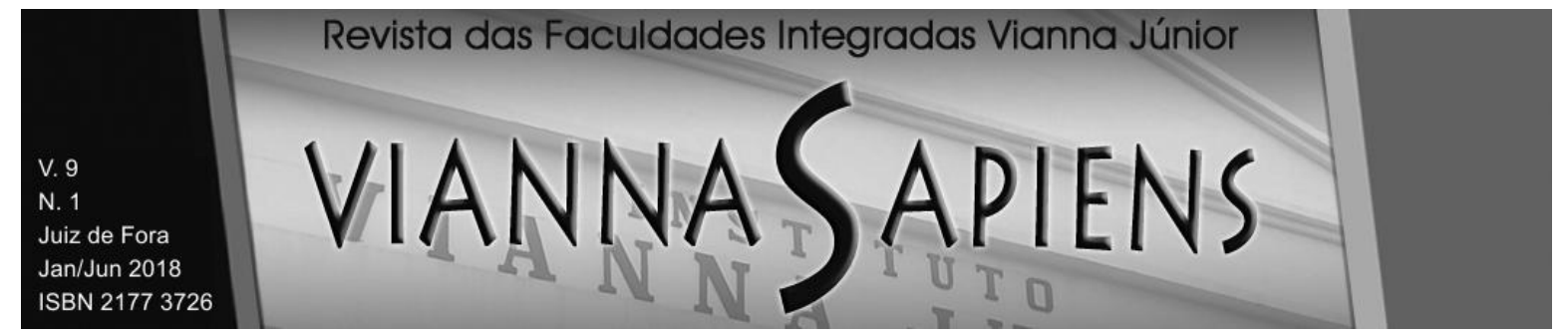

LOTMAN, I. M. Semiótica dos conceitos de 'vergonha' e 'medo'. In: Ensaios de Semiótica Soviética. Lisboa: Horizonte, 1981.

MARÍN, L.; QUEIROZ, M. S. A atualidade dos acidentes de trânsito na era da velocidade: uma visão geral. Cadernos de Saúde Pública, v.16, n.1, p. 7-21, 2000.

MASLOW, A. H. Motivation and Personality. 2 ed. New York: Harper \& Row, 1970.

MASTROIANNI, P. C.; VAZ, A. C. R.; NOTO, A. R.; GALDURÓZ, J. C. F. Análise do conteúdo de propagandas de medicamentos psicoativos. Revista de Saúde Pública, v.42, n.5, p. 968-971, 2008.

MELO, V. A. O automóvel, o automobilismo e a modernidade no Brasil (1891-1908). Revista Brasileira de Ciências do Esporte, v.30, n.1, p. 187-203, 2008.

MENEGUIN, A. M. P. L. Entre o acelerador e o freio: o motorista no discurso publicitário. Intercom. São Paulo, v. 39, n.1, p.111-138, 2016.

MESQUITA FILHO, M. Acidentes de trânsito: as consequências visíveis e invisíveis à saúde da população. Revista Espaço Acadêmico, v.11, n.128, p. 148-157, 2012.

OKIGBO, C.; MARTIN, D.; AMIENYI, O. P. Our ads 'R US: an exploratory content analysis of American advertisements. Qualitative Market Research: An International Journal, v.8, n.3, p. 312-326, 2005.

ORGANIZAÇÃO DAS NAÇÕES UNIDAS NO BRASIL - ONUBR. OMS: Brasil é o país com maior número de mortes de trânsito por habitante da América do Sul. 2015. Disponível em: <https://nacoesunidas.org/oms-brasil-e-o-pais-com-maiornumero-de-mortes-de-transito-por-habitante-da-america-do-sul/>. Acesso em 29/04/2016.

PESSÔA, L. A. G. P. Narrativas da segurança no discurso publicitário: um estudo semiótico. São Paulo: Mackenzie, 2013. 


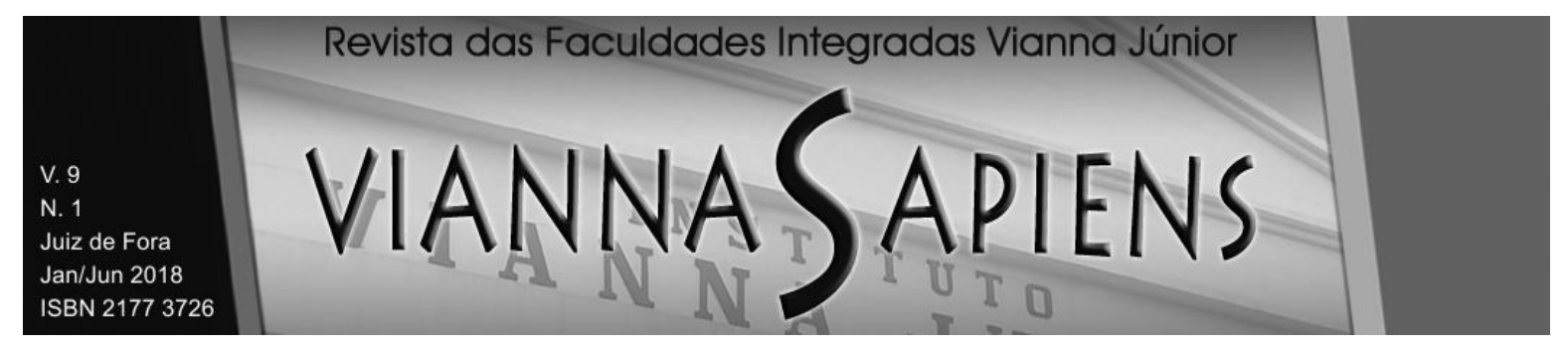

ROCHA, A.; CHRISTENSEN, C. Marketing: teoria e prática no Brasil. 2 ed. São Paulo: Atlas, 2008.

SASAKI, S.; BARBOSA-FANTIN, B. R. Segurança dos meios de locomoção na cidade de botucatu. Tekhne e Logos, v.3, n.3, p. 126-145, 2012.

STEVENS, L. A propaganda do governo e a publicidade automotiva: Disputas e contradições. Signos do Consumo, v.5, n.1, p. 19-31, 2013.

VIEIRA, V. A. Verificação do conteúdo das propagandas de empresas de serviços: um estudo descritivo e proposições de pesquisa. Revista Alcance, v. 13, n.1, p. 6990, 2006.

VIEIRA, V. A.; PETROLL, M. M. Propagandas business-to-business versus business-to-consumer: uma comparação de anúncios de serviços em revistas brasileiras. Revista de Administração Mackenzie, v.8, n.1, p. 104-127, 2007.

Recebido em 03/03/2018

Publicado em 13/08/2018 